\title{
Olfactory Cue Mediated Neonatal Recognition in Sheep, Ovis aries
}

\author{
Barend V. Burger-, Marlize Z. Viviers, Maritha Le Roux \\ Laboratory for Ecological Chemistry, Stellenbosch University, Private Bag X1, Matieland, 7602, South Africa \\ Neil J. Le Roux \\ Department of Statistics and Actuarial Science, Stellenbosch University, Private Bag X1, Matieland, 7602, South Africa \\ Jan P. I. Bekker \\ Institute for Plantbiotechnology, Stellenbosch University, Private Bag X1, Matieland, 7602, South Africa \\ John Morris \\ Mariendahl Experimental Farm, Faculty of AgriSciences, Stellenbosch University, Private Bag X1, Matieland, 7602, South Africa
}

\begin{abstract}
The strong bond between ewe and lamb formed shortly after parturition is an important factor in lamb survival. Evidence exists that a ewe can distinguish her lamb by its unique smell, but the constituents of such a putative olfactory cue have not yet been identified. We have now identified 133 volatile organic compounds associated with the wool of Döhne Merino lambs that we presume may be involved in neonatal recognition. Quantitative analysis and comparison of odor profiles of the twins of 16 ewes (9.69\% sample group) of a flock of 165 twin-bearing ewes revealed that the wool volatiles of twins are qualitatively and quantitatively similar, but differ from those of other twins or non-twin lambs in the flock. The 88 constituents present in at least $20 \%$ of the analyzed wool samples were considered as variables for multivariate analysis.
\end{abstract}

A P-value $<0.001$ was calculated, indicating that the pairing of twins according to the qualitative and quantitative composition of the wool was significant. Bioassays carried out during the lambing seasons of 2009 and 2010 confirmed the previously established role of lamb odor in ewe-lamb recognition. However, when alien lambs were dressed in jackets sprayed with synthetic mixtures formulated to match the chemical composition of the effluvia of the ewes' own lambs, ewes rejected the aliens. This is possibly because the VOCs were not released in quantitative ratios sufficiently accurate to emulate the odor of the ewes' own lambs.

Key Words: Semiochemical communication, Kin recognition, Headspace analysis, Sorptive sample enrichment, Sample enrichment probe, SEP technique, GC-MS analysis .

\section{Introduction}

Since Aristotle reportedly (Lynch et al., 1992) described the most successful way of achieving fostering in sheep was to skin a dead lamb, place the skin on a foster lamb, and confine the ewe with the foster lamb, this approach has been practiced by many sheep farmers. Sheep are seasonal breeders with large numbers of ewes giving birth during a relatively short lambing season. It is, therefore, crucial that a mother recognizes her lamb in order to provide nourishment selectively to her offspring. Although auditory and visual cues also are used, ewes appear to rely on an olfactory cue, described in other animals as an odor signature (Yamazaki et al., 1976) or signature mixture (Wyatt, 2010), which provides final assurance before allowing lambs at the udder (Lindsay, 1988).

When ewes are not in parturition and not lactating, olfactory cues play an inhibitory role in maternal responsiveness, resulting in ewes displaying indifferent or hostile behavior toward neonatal lambs (Dwyer, 2008). However, for a short period, around the time of parturition, ewes become highly interested in neonatal lambs and may even steal lambs from other ewes. During parturition, odor produced by or associated with a lamb is a powerful stimulus, and neural structures such as the olfactory bulb undergo extensive changes when exposed to such odors (Kendrick et al., 1992). The bond between ewe and lamb is established through contact within 4-6 $\mathrm{h}$ after birth. If this fails to happen, maternal interest wanes and the ewe will not accept the lamb. However, once the bond is formed, ewe and lamb can be separated for relatively long periods without disruption of bond integrity (Lindsay, 1988). The common factor that characterizes most post-partum deaths of lambs is impediment or disturbance of bond formation between ewes and offspring (Lindsay, 1988). 
In order to curtail financial losses that result from rejection of newborn lambs, a well-known phenomenon in all sheep races, farmers and scientists have examined methods of facilitating adoption of rejected lambs by ewes with ample milk. In addition to the Aristotelian method, other methods of odor transfer are practiced, albeit with limited success, by sheep farmers and have been subjected to scientific scrutiny including, for example, the transfer of the odor of a foster mother's own lamb to a rejected or orphaned lamb (Price et al., 1984, 2003; Alexander et al., 1987, 1989a, $\underline{\text { 19). }}$ ). Although sheep have been domesticated for about 11,000-12,000 years, and are regarded as one of the most studied animal species (Adams and McKinley, 1995), the olfactory cue that mediates ewe-lamb bonding has not yet been characterized. There are several sources from where the volatile organic compounds (VOCs) constituting a lamb's unique olfactory cue could be released. One possibility is a maternal label originating from amniotic fluid, milk, saliva, or some other secretion/excretion of the ewe.

Rietdorf (2002) investigated three possible sources of sheep maternal odor: colostrum, amniotic fluid, and inguinal gland secretion. Because ewes are strongly attracted to amniotic fluid for a few hours after parturition (Lévy et al., 1983; Vince et al., 1985), farmers often smear a newborn lamb with a ewe's amniotic fluid so as to strengthen the bond (Lévy et al., 2004). However, the amniotic fluid has no effect on maternal acceptance, indicating that the fluid contains cues for general attractiveness rather than individual recognition (Lévy et al., 2004). Alternatively, a lamb could be born with its own individual odor, with amniotic fluid having a supporting role in recognition by inducing a ewe to lick and groom a lamb, thus enabling the ewe to become acquainted with the lamb's olfactory profile. The interest that ewes display in the hindquarters, head, and neck areas of their lambs is well documented (Alexander et al., 1983; Price et al., 1984; Lynch et al., 1992; Houpt, 2005).

However, from our observations, it is apparent that, in general, a ewe has no preference for a specific area on a lamb's body during the initial identification process; she simply inspects the closest part of the lamb. The lamb is finally accepted at the udder with its head turned away from the head of the ewe, at which stage the ewe, perhaps for practical reasons, shows increased interest in the lamb's hindquarters. These observations are in accord with other findings that indicate that the discrimination by ewes between their own and alien lambs is mediated primarily by olfactory cues from the lamb's wool and skin, and not from a specific area on the lamb's body or amniotic fluid (Alexander and Stevens, 1981; Lynch et al., 1992; Brennan and Kendrick, 2006).

Furthermore, Kendrick et al. (1992) found that lamb odors had no influence on the activity of olfactory bulb neurons of ewes during the period before birth, but when tested after birth these odors were potent; the smell of a lamb's wool being almost as effective a stimulus as the smell of the whole lamb. Subsequently, Lévy et al. (2004) showed that ewes could recognize lambs solely through VOCs, without direct contact. Cues responsible for the individual olfactory signature of a lamb are not effective at distances greater than $250 \mathrm{~mm}$ (Alexander and Shillito, 1977; Alexander, 1978; Poindron et al., 2003), suggesting that the cues are either not very volatile or are present at very low concentrations.

Poindron et al. (2006) and Romeyer et al. (1993) showed that ewes use phenotype matching to recognize lambs. A ewe implanted with monozygotic twin embryos, and allowed to learn the odor of one of the twins after birth, recognized the second monozygotic lamb without being previously exposed to it. However, when this experiment was repeated with dizygotics, the ewe did not identify the twin after first being exposed to the other dizygotic (non-identical) twin. This experiment also shows that at least some features of the lamb's odor are genetically based (Wyatt, 2003).

Here, we report the results of qualitative and quantitative analyses of VOCs present in the cranial wool of Döhne Merino lambs, as well as results of preliminary field tests with synthetic mixtures of the identified VOCs.

\section{Material and Methods General}

All (borosilicate) glassware used for the collection of samples was washed thoroughly with distilled water, heated $\left(400^{\circ} \mathrm{C}\right)$ for at least $30 \mathrm{~min}$. to remove all traces of adsorbed organics, and then cooled immediately prior to use. Samples (1 ml) of solvents dichloromethane (DCM) (Romil, Super Purity, Cambridge, UK or Pestanal Grade, Riedel deHaën, Seelze, Germany) and tert-butyl methyl ether (TBME) (Sigma-Aldrich, anhydrous, 99.8\%, St Louis, MO, USA) were concentrated to $10 \mu \mathrm{l}$ in a nitrogen atmosphere (Reiter et al., 2003) and analyzed for impurities. These solvents were sufficiently pure for the extraction of semiochemicals. Syringes were cleaned by flushing barrels and rinsing plungers with DCM. 


\section{Sample Collection and Preparation}

A ewe flock of Döhne Merinos at Mariendahl, an experimental farm of Stellenbosch University located 14 km outside Stellenbosch, was available for study. The Döhne Merino sheep race produces a high percentage of twins. Singletonand twin-bearing ewes were housed in separate paddocks. After birth, the singleton-bearing ewes plus lambs were moved to another paddock, while the twin-bearing ewes with lambs were moved to lambing pens for 2-3 d, after which they were housed in their own paddock. Sixteen (9.69\%) of a flock of 165 twin-bearing ewes were used as a sample group.

Using a pair of scissors, wool samples (ca $200-400 \mathrm{mg}$ ) were collected from the foreheads of 32 lambs on the morning after birth. Cranial wool was used because the head of a lamb should be less contaminated with foreign matter than the rest of the body. The samples were stored in glass vials $(25 \mathrm{ml})$ with Teflon-faced septa at $-20^{\circ} \mathrm{C}$ until analyzed. The wool harvested from one lamb was sufficient for several analyses (Supplementary material, Fig. S1).

The procedures that were followed in our research were approved by the Stellenbosch University Ethics Committee: Animal Care and Use (Ethics number 11NC_BU01).

\section{Analytical Methods}

Gas chromatographic (GC) analyses were carried out with a Carlo Erba HRGC gas chromatograph (Milan, Italy) with a Grob split/splitless sample inlet and flame ionization detector operated at $220^{\circ} \mathrm{C}$ and $280^{\circ} \mathrm{C}$, respectively. Gas chromatographic data were acquired with a DELTA Chromatography Data System, Version 5.0 (Digital Solutions, Brisbane, Australia). The capillary columns were manufactured by the Laboratory for Ecological Chemistry (LECUS, Stellenbosch University) and were provided with integrated retention gaps of 1-2 $\mathrm{m}$. The following columns were used: column A [glass, $40 \mathrm{~m} \times 0.25 \mathrm{~mm}$ i.d., coated with $0.25 \mu \mathrm{m}$ of apolar PS-089-OH (DB-5 equivalent)], column B [glass, $40 \mathrm{~m} \times 0.25 \mathrm{~mm}$ i.d., coated with $0.25 \mu \mathrm{m}$ of polar AT-1000 (FFAP equivalent)], enantioselective column C [glass, $30 \mathrm{~m} \times 0.3 \mathrm{~mm}$ i.d., coated with $0.25 \mu \mathrm{m}$ of OV-1701-OH containing $10 \%$ heptakis(2,3-di-O-methyl-6-O-tertbutyldimethylsilyl)- $\beta$-cyclodextrin], and enantioselective column D [glass, $30 \mathrm{~m} \times 0.3 \mathrm{~mm}$ i.d., coated with $0.25 \mu \mathrm{m}$ of OV-1701-OH containing 10\% heptakis(2,3-di-O-acetyl-6-O-tert-butyldimethylsilyl)- $\beta$-cyclodextrin)].

Hydrogen was the carrier gas at a linear flow velocity of $50 \mathrm{~cm} \cdot \mathrm{sec}^{-1}$ (column temperature $40^{\circ} \mathrm{C}$ ). Samples were injected in the split mode, at a column temperature below $30^{\circ} \mathrm{C}$. The column temperature was increased ballistically to $40^{\circ} \mathrm{C}$, after which columns $\mathrm{A}$ and $\mathrm{B}$ were temperature programmed at $2^{\circ} \mathrm{C} \cdot \mathrm{min}^{-1}$ to $280^{\circ} \mathrm{C}$ and $250^{\circ} \mathrm{C}$, respectively. The final temperature was held for $20 \mathrm{~min}$. The enantioselective columns were programmed at $1^{\circ} \mathrm{C}$. $\mathrm{min}^{-1}$ from 40 to $220^{\circ} \mathrm{C}$. Gas chromatographic-low resolution electron impact mass spectrometric analysis (GC-LRMS) of material from wool samples was carried out on a Carlo Erba QMD 1000 instrument (Milan, Italy), using the columns and GC parameters specified above. Electron impact (EI) mass spectral data were acquired at $70 \mathrm{eV}$ from m/z 25-350. Helium was the carrier gas at a linear flow velocity of $28.6 \mathrm{~cm} \cdot \mathrm{sec}^{-1}$ (column temperature $40^{\circ} \mathrm{C}$ ). Inlet and interface temperatures were $220^{\circ} \mathrm{C}$ and $250^{\circ} \mathrm{C}$, respectively. The ion source temperature was set at $180^{\circ} \mathrm{C}$, and the pressure in the source housing was ca. $2 \times 10^{-5} \mathrm{~mm} \mathrm{Hg}$ at a column temperature of $40^{\circ} \mathrm{C}$, decreasing to ca. $1 \times 10^{-5} \mathrm{~mm} \mathrm{Hg}$ towards the end of the temperature program.

A scan rate of $0.9 \mathrm{sec} . \mathrm{scan}^{-1}$ and an interscan delay of $0.1 \mathrm{sec}$ were used. This instrumentation also was used for retention time comparisons of the volatiles in the wool samples (wool volatiles) with authentic synthetic reference compounds. Gas chromatography-mass spectrometry (GC-MS) was used to monitor the syntheses of reference compounds, and to confirm the identification of the wool volatiles by retention time comparison with commercially available synthetic compounds (Sigma-Aldrich, Cape Town) available from previous research projects, or compounds synthesized during the present study (Supplementary material). High resolution mass spectrometric data were acquired on a gas chromatograph coupled to a time-of-flight mass spectrometer (GC-TOF-HRMS), employing a Waters GCT Premier GC-MS instrument (Waters, Milford, MA, USA) fitted with capillary column E (30 m $\times 0.25 \mathrm{~mm}$ i.d., $0.25 \mu \mathrm{m}$ film, DB-5 ms, Agilent JW Scientific, Folsom, CA, USA). Helium was the carrier gas at $1 \mathrm{ml} \cdot \mathrm{min}^{-1}$.

An inlet temperature of $260^{\circ} \mathrm{C}$ was used, and samples were introduced in the split mode (split ratio 1:5) at a column temperature below $30^{\circ} \mathrm{C}$. The column temperature was then increased ballistically to $40^{\circ} \mathrm{C}$, after which the oven was programmed at $2^{\circ} \mathrm{C} \cdot \mathrm{min}^{-1}$ from 40 to $280^{\circ} \mathrm{C}$ (isothermal $5 \mathrm{~min}$.), followed by a $2^{\circ} \mathrm{C}$. $\mathrm{min}^{-1}$ ramp to $300^{\circ} \mathrm{C}$ (isothermal for $20 \mathrm{~min}$ ). El-MS data were acquired at $70 \mathrm{eV}$, scanning the range $\mathrm{m} / \mathrm{z} 35-600$ at a rate of $0.2 \mathrm{sec} / \mathrm{scan}$, with an inter-scan delay of $0.05 \mathrm{sec}$. The source temperature was $180^{\circ} \mathrm{C}$ and perfluoro-tri-n-butylamine was used as mass reference. The 
identification of the compounds associated with the cranial wool of the experimental lambs also was substantiated by the determination of retention indices (Kovats, 1958).

${ }^{1} \mathrm{H}$ and ${ }^{13} \mathrm{C}$ NMR spectra of synthesized reference compounds were recorded in $\mathrm{CDCl}_{3}$ on Varian VNMRS 300, Unity INOVA 400 and UNITY INOVA 600 NMR instruments (Varian, Palo Alto, CA, USA).

\section{Sampling Methods Conventional Sample Extraction}

Dichloromethane (DCM) and tert-butyl methyl ether (TBME) were tested for the extraction of wool volatiles. TBME $(1 \mathrm{ml})$ was found to be more effective for extracting wool samples (300-500 mg). Methyl hexanoate $(14.8 \mu \mathrm{g} / \mathrm{ml}) \mathrm{was}$ added as an internal standard. Synthetic analogs of all the compounds identified also were used as external standards. Extracts were concentrated in a nitrogen atmosphere by placing a vial into a $100-\mathrm{ml}$ beaker, covering the beaker with aluminum foil, and purging the solvent vapor from the beaker without directing the nitrogen flow into the vial (Reiter et al., 2003). During evaporation, the extracts were transferred to smaller Reacti-Vials. The concentration process took about $15 \mathrm{~h}$ to yield a final volume of ca $10 \mu \mathrm{l}$. Aliquots $(1 \mu \mathrm{l})$ of extracts were subjected to GC-MS analysis by using split and septum purge flows of 10 and $1 \mathrm{ml}^{\mathrm{min}} \mathrm{min}^{-1}$, respectively.

Headspace Sampling by Solid Phase Microextraction (SPME)

Headspace volatiles of a sample of wool $(70 \mathrm{mg})$ in a bottle $(8 \mathrm{ml})$ were sampled by SPME for $15 \mathrm{~h}$ at $50^{\circ} \mathrm{C}$ in a conventional laboratory oven with air circulation.

Headspace Sampling by Sample Enrichment Probe (SEP)

A second generation SEP50 sample enrichment probe (MasChrom Analisetegniek, Stellenbosch, South Africa), consisting of a fused silica stalk, or shaft, carrying a $50 \mathrm{~mm}$ sleeve $(47 \mathrm{mg}$ ) of polydimethylsiloxane (PDMS) tubing (Burger et al., 2006, 2011), was used to trap VOCs from wool samples for GC and GC-MS analyses. The Teflon face of a septum was pierced centrally with the sharpened back end of the SEP, and the septum positioned on the stalk so as to enable headspace sampling from an $8-\mathrm{ml}$ vial. The wool sample $(70 \mathrm{mg})$ was placed in the vial, the SEP50 installed with its lower tip clearing the sample, and, after tightening the vial cap, the SEP was exposed to the headspace at $70^{\circ} \mathrm{C}$ for $1 \mathrm{~h}$. The volatile compounds retained in the PDMS were desorbed at $220^{\circ} \mathrm{C}$ in the GC-MS. The SEP was left in the injector until completion of an analysis (Burger et al., 2006).

\section{Dimethyl Disulfide Derivatization}

The double bond positions of unsaturated VOCs of wool were determined by dimethyl disulfide (DMDS) derivatization and GC-MS analysis of the resulting adducts, similar to the method of Vincenti et al. (1987). An aliquot of a TBME extract of wool volatiles was concentrated to $5 \mu \mathrm{l}$ in a Reacti-Vial, using a slow stream of purified nitrogen. The concentrate was re-dissolved in carbon disulfide $(50 \mu \mathrm{l})$, and treated with an excess of iodine solution $(5 \mu \mathrm{l}$ of $60 \mathrm{mg}$ of $\mathrm{I}_{2}$ in $1 \mathrm{ml}$ of TBME) and DMDS $(50 \mu \mathrm{l})$.

The Reacti-Vial was sealed, and the reaction mixture was heated at $60^{\circ} \mathrm{C}$ for $40 \mathrm{~h}$. The reaction was quenched with $5 \%$ aqueous sodium thiosulfate, and the aqueous layer separated from the organic layer by centrifuging the mixture at $3,000 \mathrm{rpm}$. The organic layer was transferred to another Reacti-Vial and washed with water $(2 \times 20 \mu \mathrm{l})$, utilizing centrifugation to facilitate phase separation. The extract was concentrated and used for GC-MS analysis.

\section{Determination of Absolute Configuration of Chiral Compounds}

Enantioselective columns $C$ and $D$ were used to separate enantiomers of the chiral constituents present in wool samples.

\section{Statistical Analysis of VOCs}

Of the 133 constituents identified, only those present in $20 \%$ or more of the wool samples were considered as variables for statistical analysis, reducing the number of constituents included in the analysis to 88 . The chromatographic data used for multivariate analyses still contained a large number of variables (peak areas for these identified constituents, $\mathrm{N} \leq 88$ ) relative to the number of sample units (wool samples, $\mathrm{N} \leq 32$ ). Peak areas were normalized across all samples to produce comparable variables with zero means and unit standard deviation (Kowalski and Bender, 1972). Permutation tests were carried out to determine whether the wool of twin lambs could be grouped according to the 
qualitative and quantitative composition of VOCs present in their wool. The following null-hypothesis was tested: twin lambs cannot be grouped according to the qualitative and quantitative composition of their wool volatiles. Thus, the calculated P-value provided an indication of whether the similarities found between twin lambs could be attributed to the fact that they are twins or to random variation in the data.

Using this principle, the similarity in the odor profile of the wool of a pair of twin lambs was assessed by executing 10,000 permutation tests. The 88 constituents and their quantities in the wool of day-old lambs born during the lambing season of 2007 were used to construct a principal component analysis (PCA) biplot. Biplots can be considered as multivariate scatterplots that simultaneously give a graphical presentation of samples (lambs) and variables (identified constituents). Lambs are displayed as points on the graph while the identified constituents are displayed as linear axes.

The significance of an axis of a biplot is similar to that of an ordinary scatterplot: if a line is drawn from any point in a biplot perpendicular to a biplot axis, the value of the variable at that point can be read on the axis. In addition, the angle between any two axes approximates the correlation between two relevant variables. Constituents displayed as axes that are 90 degrees in relation to one another have no correlation with each other, and those constituents lying on axes close to one another have a high level of correlation with one another. An axis is labeled at the positive value of its calibration.

PCA biplots, permutation tests, and investigations into predictivity, were performed using R (Vienna, Austria), as described in Aldrich et al. (2004) and Gardner-Lubbe et al. (2008).

\section{Bioassays}

Bioassays were performed with singleton- and twin-bearing Döhne Merino ewes during the lambing season at Mariendahl from March to April 2009 and 2010. Singleton-bearing ewes, with their lambs, were placed in a 0.2-ha paddock within $12 \mathrm{~h}$ after parturition, while twin-bearing ewes, with lambs, were isolated in lambing pens (1.2 $\times 1.6 \mathrm{~m})$ inside a naturally illuminated and ventilated shed. All bioassays were conducted in these pens, outside in an enclosed concrete-surface arena $(12 \times 8 \mathrm{~m})$, or in paddocks (ca. $\left.10,000 \mathrm{~m}^{2}\right)$ with natural vegetation.

Exploratory bioassays were carried out during 2009 and 2010 by dressing lambs in treated cotton fleece jackets (which served as an odor-disseminating medium), and presenting alien lambs to ewes. In order to prevent, or at least curtail, odor diffusion through the jackets during the $5 \mathrm{~min}$ of the bioassay, alien lambs were fitted first with disposable diapers (Huggies, New Born, Kimberly-Clark SA, South Africa). In addition, the bodies and legs of experimental lambs were wrapped in several layers of low-density polyethylene-based film (Clorox, Rockdale, Australia). Jackets were made from new, white or pale grey, fleece cloth that had been repeatedly washed in hot water and sodium dodecyl hydrogen sulfate in a domestic washing machine and air-dried on a washing line. Pieces of the cloth were subjected to SEPheadspace analysis to ensure that the material was free from contaminants that could otherwise interfere with the bioassays.

Openings were made in the jackets for the legs, ears, eyes, and snouts of lambs, before placing the jackets on lambs. The jackets were fastened ventrally and under the chins of lambs by safety pins. The tail ends of some of these jackets were folded together so as to form artificial tails, and these were kept in shape with rubber bands (Fig. S2). Hoodless jackets were made with openings for the legs. These covered the body of a lamb from the buttocks to the shoulders. Some of the bioassays carried out during April 2010 were done with experimental ewes that had been conditioned to their own lambs wearing jackets. For these and other experiments requiring lambs to wear jackets for periods of up to $72 \mathrm{~h}$, excess cloth was cut away from the hind legs of male lambs to prevent them from wetting jackets.

In control experiments, one of the lambs of a twin-bearing ewe was removed from the lambing pen for the duration of the experiment. The other lamb was presented to a ewe from a non-adjacent pen (so as to preclude the possibility that she could have been in occasional semiochemical contact with the experimental lamb). The lamb was then diapered, wrapped and presented to its own mother and then to the other ewe, after which a new cotton jacket was added, and the lamb presented again to its mother and the other ewe. Finally, it was undressed and presented to its own mother.

Drastic measures were not used to facilitate acceptance of an alien lamb. An alien lamb was considered accepted if it was allowed at the udder and if the ewe directed no butts (Supplementary material, videos available at http://scholar.sun.ac.za/handle/10019.1/3980) or butt attempts toward it over a period of 5 min after first contact. If a 
ewe rejected an alien lamb and displayed aggressive behavior toward it, the experiment was terminated immediately and the lamb removed from the pen or experimental arena. In order to allow experimental lambs to drink, the snouts and area around the eyes were not completely covered, and thus lambs were dressed mostly in hoodless jackets. In these experiments, the lamb $(N=5)$ was presented sideways to the ewe so that the ewe could first sniff at the jacket. After completion of the experiments, the animals were kept under observation until it was clear each lamb was not permanently rejected by its mother.

Wool extracts also were tested. Approximately $8 \mathrm{~g}$ of wool were sheared from the bodies of day-old lambs and Soxhletextracted with either pentane $(N=15)$, diethyl ether $(N=4), D C M(N=4)$ or ethyl acetate $(N=1)$ for 2 h. The extracts were sprayed uniformly on new, washed fleece cloth jackets. The respective solvents were allowed to evaporate before the bioassays were carried out, always within $24 \mathrm{~h}$ after the wool had been harvested. In a further experiment, approximately $16 \mathrm{~g}$ of wool, collected from both twins of a ewe, were extracted in pentane $(\mathrm{N}=2)$ or $D C M(N=4)$. To restrict co-evaporation of VOCs from the jackets, extracts were added to a freshly cleaned, new jacket in a flange flask. The flask with its contents was cooled to $-30^{\circ} \mathrm{C}$, after which most of the solvent was removed under reduced pressure at the lowest temperature possible (between $-30^{\circ} \mathrm{C}$ and $-50^{\circ} \mathrm{C}$ ), in order to restrict co-evaporation of VOCs from the treated jackets. The residual solvent traces were allowed to evaporate before the alien lambs were dressed in the jackets.

Finally, in exploratory experiments, the responses of twin-bearing ewes to alien lambs dressed in jackets sprayed with synthetic mixtures of identified wool VOCs were investigated. The synthetic mixtures were dissolved in pentane to match the composition of the wool VOCs of an experimental ewe's own lambs (analyzed as above). The bioassays were carried out within $24 \mathrm{~h}$ after the wool had been harvested. With the exception of a few unidentified constituents, authentic synthetic samples of all the VOCs identified in the cranial wool of the experimental lambs were available.

The interpretation of the results of the behavioral experiments was based on the consensus opinion of two or three observers.

\section{Results and Discussion}

As a working hypothesis, we presumed that the odor profiles of twin lambs were identical, or at least similar, and quantitatively different from those of other lambs. Based on the assumption that the odor of a lamb is directly related to the VOC composition in the headspace of a wool sample (i.e., to the relative percentages in which all of the compounds are present in the sample's headspace, and thus in the effluvium of the lamb), it should be possible to identify and quantify the chemicals constituting the ewe-lamb recognition cue by intra- and inter-twin comparisons of the effluvia of a representative sample of lambs. The results of GC-MS analyses, as exemplified in Fig. 1 , showed that the odors in twins were indeed remarkably similar, in contrast to the differences found between the odors of lambs born to different ewes (e.g., Fig. ㄹ).

Exploratory experiments showed that the wool of day-old lambs contained only trace quantities of VOCs, and about 5$10 \%$ of high-boiling point organics (lanolin). The minute quantities of VOCs precluded the use of solvent extraction; Soxhlet extraction and the removal of solvent from extracts was expected to result in unacceptable quantitative reproducibility and, also, the injection of large quantities of organic compounds with high boiling points could have a deleterious effect on the performance of capillary GC columns. Thus, headspace analysis was used. SPME was found to be too insensitive (results not shown). An adapted version of closed-loop stripping (Grob, 1973) also was evaluated.

Although reasonable results were obtained (data not shown), this technique was rejected because the air-circulating pump became contaminated by semi-volatile compounds that could not be removed by circulating water, methanol, acetone, methanol and DCM (in that order) through the pump and purging solvent vapors from the pump by overnight pumping of purified air. Because of its high sensitivity and simplicity, the SEP technique (Burger et al., 2006, 2011) eventually was used for sample enrichment of the wool VOCs. The recently introduced term "enrichment" has gained wide acceptance, and is now preferred for sampling techniques in which the constituents of a gas sample, or the headspace of solids or liquids, are concentrated in the sample preparation step prior to introduction of the sample into the injector of the analytical instrument. A typical total ion trace (TIC) of the cranial wool volatiles of a day-old lamb is depicted in Fig. $\underline{3}$. 
Nevertheless, several wool samples also were extracted with DCM for determination of the total composition of the collected wool and for physical data required for the calculation of the composition of the concentration of the volatiles and semi-volatiles in the wool from the headspace data. The wool of day-old lambs typically contained 5-10\% moisture, 1-4\% inorganic particles, and 4-8\% extractable organic material (commonly known as lanolin). The lanolin contained traces of volatile and semi-volatile organic compounds that eluted from an apolar capillary column at temperatures up to $280^{\circ} \mathrm{C}$.

A total of 133 constituents (Table 1 ), comprising saturated and unsaturated alkanes, branched and unbranched primary alcohols, branched and unbranched aldehydes, unsaturated aldehydes, aromatic aldehydes, branched and unbranched methyl ketones, ethyl ketones, branched and unbranched carboxylic acids, unsaturated carboxylic acids, benzoic acid, esters, $\gamma$-lactones, terpenoids, 3-octanol, 2-pentylfuran, dimethyl sulfone, 3-ethyl-4-methyl-1H-pyrrole-2,5-dione, 3ethyl-3-methyl-pyrrolidine-2,5-dione, 3-methyl-4-vinyl-1H-pyrrole-2,5-dione, and 2-ethyl-3-methylpyrrolidine-2,5dione, were unambiguously identified by GC-LRMS and GC-HRMS analyses, Kovats retention index (RI) determination, and GC-MS comparison with authentic synthetic standards (Table 1). These compounds had masses from 60.05 to 410.39 , and boiling points from $119^{\circ} \mathrm{C}$ to $360^{\circ} \mathrm{C}$. The enantiomeric compositions of the chiral constituents [3-methyl-2undecanone, a series of $\gamma$-substituted $\gamma$-lactones (alkan-4-olides), 3-methylpentanal and 2-ethyl-3-methylpyrrolidine2,5-dione; Table 2] of wool were determined by GC-MS comparison with the corresponding synthetic compounds, using enantioselective columns C and D, and data published by Maas et al. (1994) and Burger et al. (2008).

The terpenoids eluted as single peaks and were presumably present in the wool as pure isomers. However, since the individual enantiomers or racemates were not available for retention time comparison, it could not be established whether this assumption was correct or not. A large number of the carboxylic acids, hydrocarbons, and alcohols identified in this study have been identified previously in lanolin (Motiuk, 1979a, $\underline{b}, \underline{1980}$; Schlossman and McCarthy, 1979). In the present investigation, these compounds were not considered as potential components of the recognition cue because of their high boiling points. The constituents of such a cue must be reasonably volatile because bond formation does not require direct physical contact between the ewe and lamb (Lévy et al., 2004).

The 133 compounds identified in this study were all present in at least $10 \%$ of the samples collected during 2007 . The number and varying concentrations of these compounds are consistent with the constraints on the design of chemical communication systems used in kin recognition which, according to Alberts (1992), requires a wide variety of compounds present in different concentrations. Approximately $50 \%$ of the total average peak area of the VOCs present in the headspace of the wool of the day-old Döhne Merino lambs consisted of only five compounds: ethyl tetradecanoate (20\%), nonanal (12\%), 6,10,14-trimethyl-2-pentadecanone (9\%), tetradecanal (4\%), and pentadecanal (4\%). The use of statistical analysis to elucidate active compounds in complex semiochemical mixtures is limited by the possibility that constituents identified as principal components in multivariate analyses might not necessarily be key components of an olfactory cue. In order to determine whether any basis existed for using twins in this study, an attempt was made to quantify intra-twin similarities and inter-twin differences in the odors of neonatal lambs by multivariate analysis of the data obtained from a randomly selected $9.69 \%$ sample of the ewe flock.

The permutation tests of the analytical data calculated a P-value $<0.001$, indicating that the pairing of twin lambs, according to the qualitative and quantitative composition of the wool, did not occur by chance, and was significant. Assuming that the odor of a lamb is related directly to the composition of the VOCs in the headspace of a wool sample, our GC-MS analyses (Figs. $\underline{2}$ and $\underline{3}$ ) showed that the odors of twins are remarkably similar, but there are differences between odors of lambs born to different ewes. Twin lambs thus possess odor profiles that are unique, with odor profiles more similar to each other than to those of other randomly selected non-twin lambs (See also Supplementary $\underline{\text { material, }}$ Fig. $\underline{\mathrm{S}}$ ). The PCA biplot depicted in Fig. 4 a provides the optimal two-dimensional presentation of the data matrix. Not all 32 samples and 88 variables are equally well represented in the biplot and axis predictivity (GardnerLubbe et al., 2008). The quality of a biplot is an overall measure of the accuracy of the two-dimensional approximation of the data matrix and hence also of the reliability of the analytical data. Furthermore, sample predictivities and axis predictivities provide detailed information about how accurately each datum point is represented in the biplot and the degree of accuracy in the predictions made from the biplot axes.

Predictivity values range from 0 to 1 , with a value of 1 representing the best predictivity. In Fig. $\underline{4 a}, \underline{b}$, only the 21 axes with predictivities $>0.800$ are displayed. The quality of display for the PCA biplots in Fig. $\underline{4 a}, b$ is $54 \%$, which reflects the proportion of variation in the data accounted for in the first two dimensions of the two-dimensional display (Gower and Hand, 1996). The other $46 \%$ is explained in the remaining 30 dimensions. In Fig. $\underline{4 b}$, the axes are not displayed in order 
so as to draw attention to the positions of the twin lambs. Each square represents a sample of wool collected from a day-old lamb, and the last three digits of the lamb's number are indicated in the biplot. Data pertaining to the lambs of each of the 16 twins are connected with black lines in Fig. $\underline{5 a, b}$. The group of lambs concentrated in the encircled area indicates that these lambs possess odor profiles that are generally similar. The fact that non-twins (e.g., lambs 12 and 434) are closer in Fig. $\underline{4 a}$, b than some twins can perhaps be explained in terms of possible variables that were not chosen in this experiment.

The 21 constituents with predictivities $>0.800$ in order of decreasing predictivity are 2,6,10,14-tetramethylhexadecane (C91), 2-pentadecanone (C79), octadecane (C89), 1-pentadecanol (C87), (5E)-6,10-dimethyl-5,9-undecadien-2-one (C60), 15-methylhexadecanal (C97), unidentified constituent C84, (E)-2-tetradecenal (C78), 2-dodecanone (C54), tridecanal (C67), decanoic acid (C53), decanal (C35), 6,10,14-trimethyl-2-pentadecanol (C95), 13-methyltetradecanal (C77), hexadecane (C72), heptadecane (C80), nonadecane (C100), 2-heptadecanone (C99), unidentified constituent C83, 6,10,14-trimethyl-2-pentadecanone (C93) and dodecanal (C57). Interestingly, all the aldehydes have maxima on the left-hand side of the plot. All the methyl ketones, except 2-dodecanone, and all the hydrocarbons and decanoic acid are highly correlated with each other. In 2009, eight, day-old twins from five of the ewes that belonged to the sample group in 2007, were available for further investigation. These twins and those used in 2007 were sired by different rams. As for the wool volatiles collected in 2007, in 2009 only the volatiles present in $20 \%$ or more of the samples collected were considered as variables for statistical analysis, which reduced the number of variables to 84 constituents.

The similarity in the odor profiles of the wool of a pair of twin lambs was again assessed by executing 10,000 permutation tests. A P-value of 0.006 was calculated, indicating that the null hypothesis was rejected, and that the twin lambs born in 2009 possessed odor profiles that were unique and more similar than those of randomly selected nontwins. A higher P-value was obtained for lambs investigated in 2009 than for those investigated in 2007, but this could be attributed to the smaller number of wool samples available in 2009. The flock of ewes used in this project is being used for a long-term sheep breeding study at the Faculty of AgriSciences, and thus we could not carry out an experiment examining whether wool volatiles of offspring produced by the same parents are quantitatively and qualitatively similar from one lambing season to the next. A comparison of wool volatiles from lambs born in 2007 and 2009 from the same ewes, but with different fathers, showed that odor profiles of the 2 years were not different, with nearly all the constituents identified in wool in 2007 also present in 2009.

However, the PCA biplot (Fig. $\underline{5}$ ) shows a definite separation between wool volatiles from lambs born in 2007 and those born in 2009, indicating substantial quantitative differences. This provides evidence that the odor profiles of lambs born of the same ewe, but sired by different rams, are not identical. We are studying this aspect in more detail. The quality of display of the PCA biplot (only the 20 constituents with predictivities $>0.800$ are displayed) in Fig. $\underline{5}$ is $56 \%$. The constituents, in order of decreasing predictivity, are tridecane (C46), 13-methyltetradecanal (C77), 3-octanone (C16), 1heptanol (C15), hexanal (C4), unidentified constituent C64, tridecanal (C67), (E)-2-tetradecenal (C78), octanal (C19), (E)2-nonenal (C30), 2-pentadecanone (C79), tetradecanal (C73), dodecanal (C57), hexadecane (C72), 6-methyl-2heptanone (C14), (E)-2-octenal (C23), heptanal (C8), N-methyl-2-piperidinone (C29), hexadecanal (C90) and 2,5dimethylpyrimidine (C11). It is clear from Fig. $\underline{5}$ that lambs born in 2007 have larger quantities of all these compounds. The figure suggests that the two nitrogen containing constituents, N-methyl-2-piperidinone (C29) and 2,5dimethylpyrimidine (C11), are highly correlated.

All the hydrocarbons, ketones and aldehydes, except (E)-2-octenal (C23), also correlate reasonably well with each other. Price et al. (1984), placed nylon stockinettes worn by lambs for $72 \mathrm{~h}$ on alien lambs, which were then presented to ewes. Initially, $38 \%$ of alien lambs were accepted immediately and another $50 \%$ accepted over a further $36 \mathrm{~h}$. More drastic measures have been used in other studies to force ewes to accept alien lambs treated with various odors or synthetic materials. For example, ewes were tethered to prevent them from displaying their typical udder denial behavior in experiments that continued over periods of up to $72 \mathrm{~h}$ (Alexander et al., 1987, 1989b). We carried out similar experiments. However, the experimental lambs were diapered and wrapped in polyethylene film to impede the diffusion of odor of the lambs into the treated jackets. In our control experiments, carried out to test the effect of diapers and polyethylene film, the majority of ewes rejected the wrapped and dressed alien lambs (Table $\underline{3}$ ). A smaller majority of ewes rejected their own wrapped and dressed lambs. Although the lambs did not bleat much, it is possible that these ewes could have recognized their own lambs by auditory or visual cues. It was apparent, nevertheless, that the diapers plus polyethylene film were sufficiently impermeable to restrict diffusion of wool volatiles into the cotton jackets during the short bioassays (ca $5 \mathrm{~min}$ ). The results in Table $\underline{3}$ draw attention to the problems involved in the interpretation of various behavioral responses of ewes when approached by an alien lamb. 
The mothering instinct of ewes varies: some tolerate the presence of an alien lamb as long as it keeps its distance, while others react aggressively, butting the lamb. The behavior of ewes also varies depending on the number of lambs they have mothered. Young ewes are normally more suspicious and more aggressive than more experienced ewes, perhaps because older ewes have become accustomed to the presence of observers. In bioassays, typical behavioral patterns of ewes were observed, ranging from total rejection to enthusiastic acceptance, including, immediate and repeated aggressive butting of the lamb, one or more less aggressive buts, moving in circles to prevent the lamb from getting at the udder, stamping of a hind foot on the side of the approaching lamb, stepping gently aside, allowing the lamb to approach, allowing the lamb to drink for a few moments before moving away or butting it, allowing the lamb to drink for longer periods before moving away or, finally, accepting the lamb and uttering low grunts of acceptance and/or encouragement.

The reaction of the ewe also depended on how thirsty the lamb was, or on or how persistent it was at getting to the udder. It was clear that some lambs smelled or in some other way realized that an experimental ewe was not its mother. In some cases, the ewe and alien lamb simply avoided each other, a situation that made it difficult to decide whether the ewe rejected the lamb or vice versa. A small minority of ewes did not accept any lamb. In another set of control experiments, we observed a ewe aggressively butting a jacketed alien lamb without having sniffed at it and afterwards even rejecting her own twin lambs for more than an hour. In further experiments carried out in 10,000-m ${ }^{2}$ paddocks, lambs of singleton-bearing ewes wore hoodless cotton fleece jackets for $72 \mathrm{~h}$. Alien lambs, dressed in these jackets and presented to the respective ewes, were all accepted by ewes, without any of the typical signs of rejection (acceptance rate 100\%; $N=6$ ). The experimental lambs then were undressed and returned to their mothers and were all immediately accepted. One of these jackets was stored in a glass jar and the VOCs in the headspace analyzed by GCMS.

Not all the previously identified VOCs were detected (Table $\underline{1}$ ), probably because of partial evaporation of the more volatile constituents during the bioassay. On the other hand, no compounds other than those listed in Table 1 were detected. Because our qualitative chemical analyses were carried out on lambs born to twin-bearing ewes, we conducted similar bioassays with the twin-bearing ewes. An acceptance rate of lambs of only $62 \%(N=13)$ was obtained. The difference in acceptance rates between singleton- and twin-bearing ewes could possibly be ascribed to increased stress on the twin-bearing ewes due to the experiments being carried out in a concrete arena or in small lambing pens in a shed housing about 40 other ewes with twins (as opposed to the paddocks for the singleton-ewe trial). Alternatively, the absence of the second twin during the experiment may also have contributed to the stress of these ewes. Similar experiments, spraying extracts of $8 \mathrm{~g}$ of lamb wool on new washed fleece cloth jackets were carried out. In five ( $20 \%$; pentane, $N=4$; dichloromethane, $N=1$ ) of the experiments, the alien lambs were accepted by ewes.

Although the small sample size precluded meaningful statistical analysis, we suspect that selective co-evaporation of some of the more volatile compounds with the solvent could have contributed to the low acceptance rate. Headspace analyses of jackets treated with these wool extracts, or with mixtures of synthetic VOCs, revealed that VOCs are not released from the treated jackets in the same ratios in which they are present in the wool or in the synthetic mixtures. These results showed that the volatile, apolar compounds, in particular, are prone to co-evaporation with the solvent. It is also possible that the dissemination of VOCs from cotton cloth differed from that of lamb's wool, or that some constituents were converted to other products during Soxhlet extraction. A more concentrated extract of $16 \mathrm{~g}$ (collected from both twins of the ewes) of wool was applied to the jackets, with solvent evaporated at low temperature so as to minimize the co-evaporation of VOCs. Ewes $(N=6)$ rejected all the treated alien lambs, although they did sniff at the jackets for longer than in previous bioassays before rejecting the aliens.

Finally, twin-bearing ewes rejected all $(\mathrm{N}=4)$ the alien lambs dressed in jackets sprayed with mixtures of synthetic VOCs. With the exception of a few unidentified constituents, authentic synthetic samples of all the VOCs identified in the cranial wool of lambs were available. Therefore, for these experiments we did not have to select only the 21 constituents with predictivities $>0.800$, as in the statistical analyses of our analytical results. Our observations in these experiments suggested that cues other than lamb odor might be used by ewes when confronted with a decision of whether to accept or reject a lamb. In the experiments we could not preclude alien lambs from bleating, nor could we cover the heads and snouts of the lambs in such a way that they could still see and drink while preventing ewes from finding unprotected parts of the lambs to sniff at. The jackets appeared to hamper the normal persistence of lambs to get at the udder, and the awkward gait of lambs dressed in this manner could have triggered their rejection. 
Future work will focus on finding a more reliable bioassay, and on devising methods for dissemination of the VOCs in natural concentrations and ratios.

\section{Acknowledgements}

Financial support by the NRF and Stellenbosch University is gratefully acknowledged. We thank the experimental farm of Stellenbosch University, Mariendahl, for making experimental sheep available for this research and for invaluable advice and assistance. 
Table 1

Volatile organic compounds of the cranial wool of Döhne Merino lambs collected during the lambing seasons of 2007 and 2009. Constituents are grouped according to compound class

\begin{tabular}{|c|c|c|c|c|}
\hline \multirow{2}{*}{ No. } & \multirow{2}{*}{ Compound } & \multicolumn{2}{|c|}{ Column } & \multirow{2}{*}{ Remarks } \\
\hline & & Apolar & Polar & \\
\hline C10 & Nonane & $\sqrt{ }$ & & $b, c, d, k, m$ \\
\hline C2O & Decane & | & & $b, c, d, k, m, o$ \\
\hline $\mathrm{C} 28$ & Undecane & $\checkmark$ & & $b, c, d, o$ \\
\hline $\mathrm{C} 36$ & Dodecane & $\checkmark$ & | & $b, c, d, o$ \\
\hline C46 & |Tridecane & $\checkmark v$ & & $b, c, d, j, o$ \\
\hline C58 & Tetradecane & $\checkmark$ & $\checkmark$ & $b, c, d, j, n, o$ \\
\hline C72 & Hexadecane & $\checkmark$ & & $b, c, d, j, o$ \\
\hline C80 & Heptadecane & $\checkmark$ & & $b, c, d, j, o$ \\
\hline C89 & Octadecane & $\checkmark$ & & $b, c, d, j, o$ \\
\hline C100 & Nonadecane & $\sqrt{ }$ & & $b, c, d, j, o$ \\
\hline C44 & 1-Tridecene & $\sqrt{ }$ & & $b, c, d, f, o$ \\
\hline C55 & 1-Tetradecene & $\checkmark$ & & $b, c, d, f, m, o$ \\
\hline C66 & 1-Pentadecene & $\checkmark$ & & $b, c, d, f, o$ \\
\hline C118 & 1-Pentacosene & $\checkmark$ & & $b, c, e$ \\
\hline C120 & 1-Hexacosene & $\checkmark v$ & & $b, c, e$ \\
\hline $\mathrm{C} 2$ & 1-Pentanol & $\checkmark$ & & $b, c, d, k$ \\
\hline C15 & 1-Heptanol & $\checkmark$ & $\checkmark$ & $b, c, d, o$ \\
\hline $\mathrm{C} 25$ & 1-Octanol & $\checkmark$ & $\checkmark$ & $b, c, d, j, o$ \\
\hline C33 & |1-Nonanol & $\checkmark$ & | & $b, c, d, o$ \\
\hline P10 & 1-Tridecanol & & $\| \sqrt{ }$ & $b, c, d$ \\
\hline C75 & 1-Tetradecanol & $\checkmark$ & $\checkmark$ & $b, c, d, j, l$ \\
\hline C87 & 1-Pentadecanol & $\checkmark$ & & $b, c, d, j, l, o$ \\
\hline C98 & 1-Hexadecanol & $\checkmark$ & $\checkmark$ & $b, c, d, j, l, m$ \\
\hline C108 & 1-Octadecanol & $\checkmark$ & & $b, c, d, j, l$ \\
\hline C114 & 1-Eicosanol & $\checkmark$ & & $b, c, d, j$ \\
\hline C116 & 1-Heneicosanol & $\checkmark$ & & $b, c, e, j$ \\
\hline P1 & 3-Methyl-1-butanol & & $\checkmark$ & $b, c, d$ \\
\hline C6 & 4-Methyl-1-pentanol & $\checkmark$ & $\checkmark$ & $b, c, d$ \\
\hline $\mathrm{P} 2$ & 3-Octanol & & $\checkmark$ & $b, c, d$ \\
\hline C4 & Hexanal & $\sqrt{ }$ & & $b, c, d, k$ \\
\hline C8 & Heptanal & $\checkmark$ & $\sqrt{ }$ & $b, c, d, k, o$ \\
\hline C19 & Octanal & $\checkmark$ & $\checkmark$ & $b, c, d, o$ \\
\hline $\mathrm{C} 27$ & Nonanal & $\checkmark$ & $\checkmark$ & $b, c, d, o$ \\
\hline C35 & Decanal & $\checkmark$ & $\checkmark$ & $b, c, d, o$ \\
\hline C45 & Undecanal & $\checkmark$ & & $b, c, d, o$ \\
\hline C57 & Dodecanal & $\checkmark$ & $\checkmark$ & $b, c, d, o$ \\
\hline
\end{tabular}




\begin{tabular}{|c|c|c|c|c|}
\hline \multirow{2}{*}{ No. } & \multirow{2}{*}{ Compound } & \multicolumn{2}{|l|}{ Column } & \multirow{2}{*}{ Remarks } \\
\hline & & Apolar & Polar & \\
\hline C67 & Tridecanal & $\checkmark$ & $\checkmark$ & b,c,d,o \\
\hline C73 & Tetradecanal & $\checkmark$ & $\checkmark$ & $\| b, c, d, o$ \\
\hline C81 & Pentadecanal & $\checkmark$ & $\checkmark$ & $\mid b, c, d, o$ \\
\hline C90 & Hexadecanal & $\checkmark$ & & $b, c, d, o$ \\
\hline C101 & Heptadecanal & $\checkmark$ & & $b, c, d, o$ \\
\hline C105 & Octadecanal & $\checkmark$ & & $b, c, d$ \\
\hline C1 & 3-Methylpentanal & $\checkmark$ & & $b, c, d, h$ \\
\hline $\mathrm{C} 24$ & 7-Methyloctanal & $\checkmark$ & & $b, c, d, e, m, o$ \\
\hline C31 & 8-Methylnonanal & $\checkmark$ & & $b, c, d, e, o$ \\
\hline C41 & 9-Methyldecanal & $\checkmark$ & & $b, c, d, e, o$ \\
\hline C51 & 10-Methylundecanal & $\checkmark$ & $\checkmark$ & $b, c, d, e, o$ \\
\hline $\mathrm{C68}$ & 12-Methyltridecanal & $\checkmark$ & & $\mathrm{b}, \mathrm{c}, \mathrm{d}, \mathrm{e}$ \\
\hline C77 & 13-Methyltetradecanal & $\checkmark$ & & $b, c, d, e, o$ \\
\hline C86 & 14-Methylpentadecanal & $\checkmark$ & & $\mathrm{b}, \mathrm{c}, \mathrm{d}, \mathrm{e}, \mathrm{m}, \mathrm{o}$ \\
\hline C97 & 15-Methylhexadecanal & $\checkmark$ & & $b, c, d, e, m$ \\
\hline $\mathrm{C} 23$ & (E)-2-Octenal & $\checkmark$ & $\checkmark$ & $b, c, d, e, o$ \\
\hline C30 & (E)-2-Nonenal & $\checkmark$ & $\checkmark$ & $b, c, d, e, o$ \\
\hline $\mathrm{C} 40$ & (E)-2-Decenal & $\checkmark$ & $\checkmark$ & $b, c, d, e, o$ \\
\hline C50 & (E)-2-Undecenal & $\checkmark$ & $\checkmark$ & $b, c, d, e, f, o$ \\
\hline C62 & (E)-2-Dodecenal & $\checkmark$ & & $b, c, d, e, m, o$ \\
\hline C78 & |(E)-2-Tetradecenal & $\checkmark$ & & |b,c,d,e \\
\hline C13 & Benzaldehyde & $\checkmark$ & & $b, c, d, n, o$ \\
\hline $\mathrm{C} 22$ & Phenylacetaldehyde & $\checkmark$ & & $b, c, d, n, o$ \\
\hline C17 & 2-Octanone & $\checkmark$ & $\checkmark$ & $b, c, d, k, o$ \\
\hline $\mathrm{C} 26$ & 2-Nonanone & $\checkmark$ & & $b, c, d, o$ \\
\hline C34 & 2-Decanone & $\checkmark$ & $\checkmark$ & $b, c, d, o$ \\
\hline $\mathrm{C} 43$ & 2-Undecanone & $\checkmark$ & & $b, c, d, o$ \\
\hline C54 & 2-Dodecanone & $\checkmark$ & $\checkmark$ & $b, c, d, o$ \\
\hline C65 & 2-Tridecanone & $\checkmark$ & $\checkmark$ & $b, c, d, o$ \\
\hline C71 & 2-Tetradecanone & $\checkmark$ & $\checkmark$ & $b, c, d$ \\
\hline C79 & 2-Pentadecanone & $\checkmark$ & $\checkmark$ & $b, c, d, o$ \\
\hline C99 & 2-Heptadecanone & $\checkmark$ & $\checkmark$ & $b, c, d, o$ \\
\hline C14 & 6-Methyl-2-heptanone & $\checkmark$ & $\checkmark$ & $b, c, d, k, o$ \\
\hline C47 & 3-Methyl-2-undecanone & $\checkmark$ & & $b, c, d, e, g$ \\
\hline C16 & 3-Octanone & $\checkmark$ & & $\mathrm{b}, \mathrm{c}, \mathrm{d}, \mathrm{o}$ \\
\hline P4 & 3-Decanone & & $\checkmark$ & $b, c, d$ \\
\hline P3 & Acetic acid & & $\checkmark$ & $b, c, d$ \\
\hline P5 & Propanoic acid & & $\checkmark$ & $b, c, d$ \\
\hline
\end{tabular}




\begin{tabular}{|c|c|c|c|c|}
\hline \multirow{2}{*}{ No. } & \multirow{2}{*}{ Compound } & \multicolumn{2}{|l|}{ Column } & \multirow{2}{*}{ Remarks } \\
\hline & & Apolar & Polar & \\
\hline P6 & Butanoic acid & & $\checkmark$ & b,c,d \\
\hline P7 & Hexanoic acid & & $\checkmark$ & $\mid b, c, d$ \\
\hline P8 & Heptanoic acid & & $\checkmark$ & $\mid b, c, d$ \\
\hline P9 & Octanoic acid & & $\checkmark$ & $b, c, d, j$ \\
\hline $\mathrm{C} 42$ & Nonanoic acid & $\checkmark$ & $\checkmark$ & $b, c, d, j$ \\
\hline C53 & Decanoic acid & $\checkmark$ & $\checkmark$ & $b, c, d, j$ \\
\hline C69 & Dodecanoic acid & $\checkmark$ & $\checkmark$ & $b, c, d, j, m$ \\
\hline C85 & Tetradecanoic acid & $\checkmark$ & $\checkmark$ & $b, c, d, j, o$ \\
\hline C94 & Pentadecanoic acid & $\checkmark$ & $\checkmark$ & $b, c, d, j, n, o$ \\
\hline C104 & Hexadecanoic acid & $\checkmark$ & $\checkmark$ & $b, c, d, j, m, o$ \\
\hline C107 & Heptadecanoic acid & $\checkmark$ & & $b, c, d, j$ \\
\hline C112 & Octadecanoic acid & $\checkmark$ & $\checkmark$ & $b, c, d, j$ \\
\hline C115 & Eicosanoic acid & $\checkmark$ & $\checkmark$ & $b, c, d, j$ \\
\hline C117 & Heneicosanoic acid & $\checkmark$ & & $b, c, d, j$ \\
\hline C119 & Docosanoic acid & $\checkmark$ & & $b, c, d, j$ \\
\hline C82 & 12-Methyltridecanoic acid & $\checkmark$ & & $b, c, d, e, j$ \\
\hline C102 & 14-Methylpentadecanoic acid & $\checkmark$ & $\checkmark$ & $b, c, d, e, j$ \\
\hline C106 & 15-Methylhexadecanoic acid & $\checkmark$ & & $b, c, d, e, j$ \\
\hline C113 & 17-Methyloctadecanoic acid & $\checkmark$ & & $b, c, d, e, j$ \\
\hline C103 & (Z)-9-Hexadecenoic acid & $\checkmark$ & $\checkmark$ & $b, c, d, f$ \\
\hline C110 & $(\mathrm{Z}, \mathrm{Z})-9,12$-Octadecadienoic acid & $\checkmark$ & $\checkmark$ & $b, c, d$ \\
\hline C111 & (Z)-9-Octadecenoic acid & $\checkmark$ & $\checkmark$ & $b, c, d, f$ \\
\hline C32 & Benzoic acid & $\checkmark$ & $\checkmark$ & $b, c, d$ \\
\hline C88 & Ethyl tetradecanoate & $\checkmark$ & $\checkmark$ & $b, c, d, o$ \\
\hline C92 & Isopropyl tetradecanoate & $\checkmark$ & & $b, c, d, e, o$ \\
\hline C48 & Nonan-4-olide & $\checkmark$ & $\checkmark$ & $b, c, d, g, o$ \\
\hline C61 & Decan-4-olide & $\checkmark$ & & $b, c, d, g$ \\
\hline C76 & Dodecan-4-olide & $\checkmark$ & & $b, c, d, g$ \\
\hline C109 & Hexadecan-4-olide & $\checkmark$ & & $b, c, d, g$ \\
\hline C56 & 6,10-Dimethyl-2-undecanone & $\checkmark$ & & $b, c, d, h$ \\
\hline $\mathrm{C60}$ & (5E)-6,10-Dimethyl-5,9-undecadien-2-one & $\checkmark$ & & $\mathrm{b}, \mathrm{c}, \mathrm{d}, \mathrm{o}$ \\
\hline C91 & 2,6,10,14-Tetramethyl-hexadecane & $\checkmark$ & & $\mathrm{b}, \mathrm{c}, \mathrm{d}, \mathrm{h}$ \\
\hline $\mathrm{C93}$ & 6,10,14-Trimethyl-2-pentadecanone & $\checkmark$ & $\checkmark$ & $\mathrm{b}, \mathrm{c}, \mathrm{d}, \mathrm{h}, \mathrm{o}$ \\
\hline C95 & 6,10,14-Trimethyl-2-pentadecanol & $\checkmark$ & & $\mathrm{b}, \mathrm{c}, \mathrm{d}, \mathrm{h}$ \\
\hline C122 & Squalene & $\checkmark$ & $\checkmark$ & $b, c, d$ \\
\hline C5 & 2-Methylpyrimidine & $\checkmark$ & $\checkmark$ & $b, c, d$ \\
\hline C11 & 2,5-Dimethylpyrimidine & $\checkmark$ & $\checkmark$ & $b, c, d$ \\
\hline C29 & N-Methyl-2-piperidinone & $\checkmark$ & $\checkmark$ & $b, c, d$ \\
\hline
\end{tabular}




\begin{tabular}{|c|c|c|c|c|}
\hline \multirow{2}{*}{ No. } & \multirow{2}{*}{ Compound } & \multicolumn{2}{|l|}{ Column } & \multirow{2}{*}{ Remarks } \\
\hline & & Apolar & Polar & \\
\hline C37 & |3-Ethyl-4-methyl-1H-pyrrole-2,5-dione & $\checkmark$ & $\checkmark$ & $b, c, i, n, o$ \\
\hline C38 & |3-Ethyl-4-methylpyrrolidine-2,5-dione & $\checkmark$ & $\checkmark$ & |b,i,g,n \\
\hline C39 & |3-Methyl-4-vinyl-1H-pyrrole-2,5-dione & $\checkmark$ & $\checkmark$ & $b, c, i, n$ \\
\hline C9 & Dimethyl sulfone & $\checkmark$ & $\checkmark$ & $b, c, d, n, o$ \\
\hline C18 & 2-Pentylfuran & $\checkmark$ & & $b, c, d, o$ \\
\hline C124 & Cholest-5-en-3 $\beta$-ol & $\checkmark$ & & $b, c, d, j$ \\
\hline C3 & Unidentified & $\checkmark$ & & \\
\hline C7 & Unidentified & $\checkmark$ & & \\
\hline C12 & Unidentified & $\checkmark$ & $\checkmark$ & $n$ \\
\hline C21 & Unidentified & $\checkmark$ & & \\
\hline C49 & Unidentified & $\checkmark$ & $\checkmark$ & $n, 0$ \\
\hline $\mathrm{C} 52$ & Unidentified & $\checkmark$ & & 0 \\
\hline C59 & Unidentified & $\checkmark$ & & $\|$ \\
\hline C63 & Unidentified & $\checkmark$ & $\checkmark$ & | \\
\hline C64 & Unidentified & $\checkmark$ & & 0 \\
\hline C70 & Unidentified & $\checkmark$ & & 0 \\
\hline C74 & Unidentified & $\checkmark$ & & $\mathrm{m}$ \\
\hline C83 & Unidentified & $\checkmark$ & & $\mathrm{m}$ \\
\hline $\mathrm{C} 84$ & Unidentified & $\checkmark$ & & $b, m$ \\
\hline C96 & Unidentified & $\checkmark$ & & $b, c, o$ \\
\hline C121 & Unidentified & $\checkmark$ & & \\
\hline C123 & Unidentified & $\checkmark$ & & \\
\hline
\end{tabular}

a: Constituents identified using apolar column A are numbered from C1 to C124 and those identified using polar column B numbered from P1 to P10

b: Low-resolution electon ionization mass spectrum

c: Library spectrum (NBS and/or NIST)

d: Retention time comparison with synthetic compound

e: Retention index

f: Double bond localization by dimethyl disulfide derivatization and gas chromatography-mass spectrometry

g: Absolute configuration given in Table $\underline{2}$

h: Absolute configuration not determined

i: Tentative identification

j: Compounds previously identified in lanolin (Schlossman and McCarthy, 1979; Motiuk, 1979a, 1979b, 1980)

k: Compounds previously identified in wool (Lisovac and Shooter, 2003)

I: Compounds previously identified in inguinal gland of ewes (Rietdorf, 2002)

$\mathrm{m}$ : Compounds identified in the wool during the lambing season of 2007 that were not identified in the lambing season of 2009

n: Compounds identified in the wool during the lambing season of 2009 that were not identified in the lambing season of 2007

o: Compounds identified in cotton fleece jacket left on lamb for 3 days 
Table 2

Enantiomeric composition of chiral constituents of wool determined by gas chromatography using columns $C$ and $D^{a}$

\begin{tabular}{|l|l|l||}
\hline Compounds & Enantiomeric ratio (R:S) \\
\hline C38 & 3-Ethyl-4-methylpyrrolidine-2,5-dione & $54: 46\left(\mathrm{~N}=1, \mathrm{C}^{\mathrm{c}}\right)$ \\
\hline C47 & 3-Methyl-2-undecanone & $91: 9$ to 100:0 $(\mathrm{N}=4, \mathrm{C})$ \\
\hline \hline C48 & Nonan-4-olide & $69: 31$ to $78: 22(\mathrm{~N}=5, \mathrm{C})$ \\
\hline C61 & Decan-4-olide & $58: 42$ to $74: 26(\mathrm{~N}=3, \mathrm{C})$ \\
\hline C76 & Undecan-4-olide & $66: 34(\mathrm{~N}=1, \mathrm{C})$ \\
\hline C109 & Hexadecan-4-olide & $54: 46\left(\mathrm{~N}=1, \mathrm{D}^{\mathrm{d}}\right)$ \\
\hline
\end{tabular}

${ }^{a}$ The ratios were determined by integration of single ion plots of the base peaks of the individual enantiomers. The quantitative data are given in the order of elution of the enantiomers from column $\mathrm{C}$ or $\mathrm{D}$. In some samples, one or both of the enantiomers co-eluted with other constituents and could thus not be quantified, which accounts for the difference in the number of listed samples $(\mathrm{N})$

border of elution unknown

'Enantioselective column C

dEnantioselective column D

\section{Table 3}

Efficacy of diapering and wrapping experimental lambs in polyethylene foil in order to curtail the release of the recognition cue during bioassays ${ }^{a}$

\begin{tabular}{|c|c|c|c|c|c|c|}
\hline & \multirow{2}{*}{\begin{tabular}{|l|} 
Alien lamb \\
Naked
\end{tabular}} & Own lamb & Alien lamb & Own lamb & Alien lamb & \multirow{2}{*}{\begin{tabular}{|l} 
Own lamb \\
Naked afterwards \\
\end{tabular}} \\
\hline & & \multicolumn{2}{|c|}{ Diapered and wrapped } & \multicolumn{2}{|c|}{$\begin{array}{l}\text { Diapered, wrapped and } \\
\text { jacketed }\end{array}$} & \\
\hline $\begin{array}{l}\text { Ewe } 79 \\
\text { Lamb } \\
298\end{array}$ & Rejected $^{\mathrm{b}}$ & Rejected & $\begin{array}{l}\text { Rejected without } \\
\text { being sniffed at }\end{array}$ & Rejected & Rejected & $\begin{array}{l}\text { No sign of rejection; } \\
\text { lamb did not attempt } \\
\text { to drink }{ }^{c}\end{array}$ \\
\hline $\begin{array}{l}\text { Ewe } 298 \\
\text { Lamb } 79\end{array}$ & \begin{tabular}{|l|} 
Avoided by \\
ewe
\end{tabular} & \begin{tabular}{|l} 
Rejected; did \\
not attempt to \\
drink
\end{tabular} & Rejected & Rejected & Rejected & $\begin{array}{l}\text { Accepted } \\
\text { immediately }^{d}\end{array}$ \\
\hline $\begin{array}{l}\text { Ewe } 204 \\
\text { Lamb } 96\end{array}$ & \begin{tabular}{|l|} 
Avoided by \\
ewe
\end{tabular} & \begin{tabular}{|l|} 
Accepted at the \\
udder, then \\
rejected
\end{tabular} & $\begin{array}{l}\text { Did not attempt to } \\
\text { drink; ewe showed } \\
\text { no aggression }\end{array}$ & $\begin{array}{l}\text { Ewe avoided } \\
\text { lamb; no } \\
\text { aggression }\end{array}$ & $\begin{array}{l}\text { Did not } \\
\text { attempt to } \\
\text { drink }\end{array}$ & $\begin{array}{l}\text { No sign of rejection; } \\
\text { lamb did not attempt } \\
\text { to drink }\end{array}$ \\
\hline $\begin{array}{l}\text { Ewe } 188 \\
\text { Lamb } 78\end{array}$ & Rejected & $\begin{array}{l}\text { Accepted at the } \\
\text { udder }\end{array}$ & Rejected & $\begin{array}{l}\text { Accepted at the } \\
\text { udder }\end{array}$ & Rejected & Accepted immediately \\
\hline $\begin{array}{l}\text { Ewe } 78 \\
\text { Lamb } \\
188\end{array}$ & $\begin{array}{l}\text { Avoided by } \\
\text { ewe }\end{array}$ & $\begin{array}{l}\text { Accepted at the } \\
\text { udder }\end{array}$ & $\begin{array}{l}\text { Avoided ewe; did not } \\
\text { attempt to drink }\end{array}$ & $\begin{array}{l}\text { Avoided by ewe; } \\
\text { did not attempt } \\
\text { to drink }\end{array}$ & $\begin{array}{l}\text { Ewe avioded } \\
\text { lamb }\end{array}$ & Accepted immediately \\
\hline Totals ${ }^{\mathrm{e}}$ & $\begin{array}{l}\text { Rejected } \\
100 \%\end{array}$ & Rejected 60\% & Rejected $80 \%$ & ||Rejected $80 \%$ & $\begin{array}{l}\text { Rejected } \\
80 \%\end{array}$ & Accepted 100\% \\
\hline
\end{tabular}

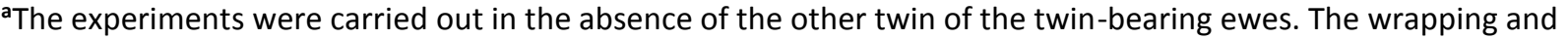
dressing procedure is described in the text

bBased on butting of the lamb and/or various ways of avoiding contact with the lamb

'Probably due to the lamb being awkwardly dressed

'Immediately accepted at the udder; in some cases accompanied by ewe's typical low grunts encouraging the lamb to drink

${ }^{\mathrm{e}}$ Based on consensus of opinion of two observers 


\section{Figures}

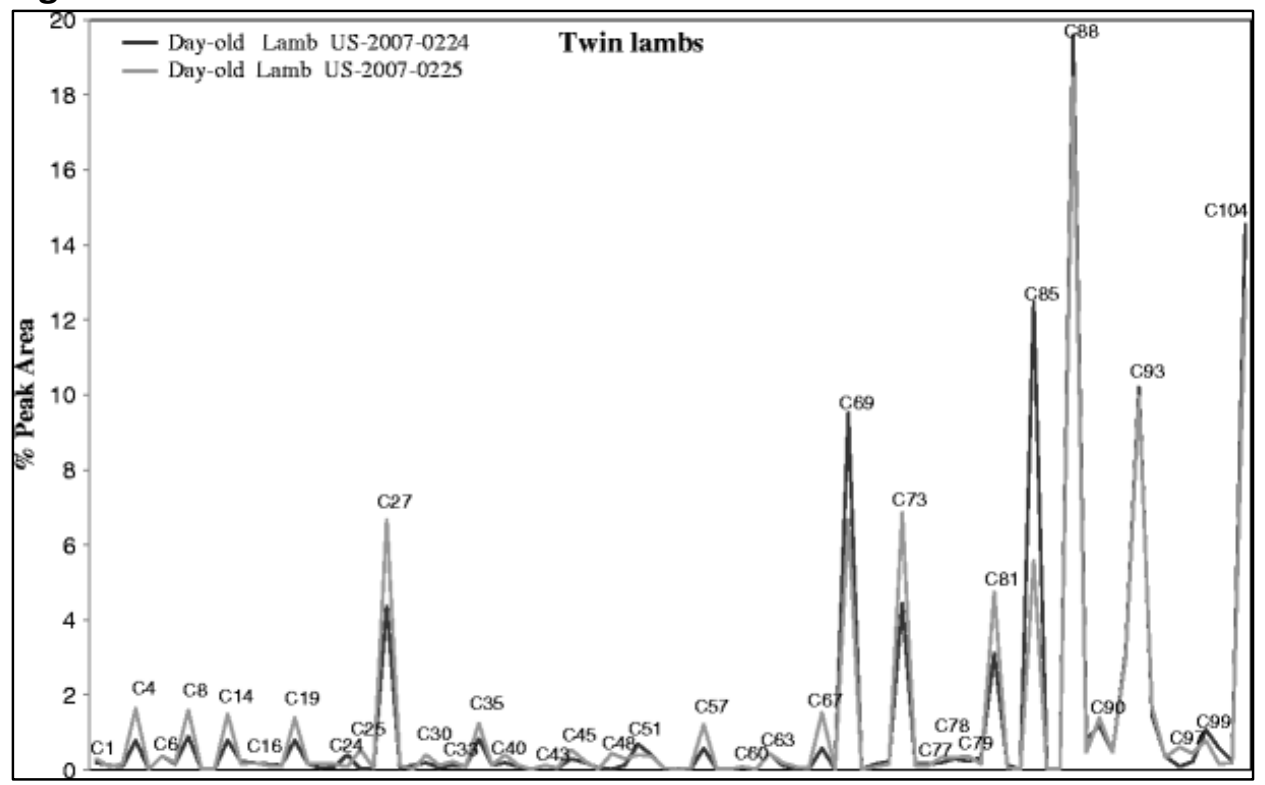

Fig. 1 Comparison of the percentage peak areas derived from mass chromatograms of the sample-enrichment-probeenriched wool volatiles of day-old twin lambs US-2007-0224 (black) and US-2007-0225 (grey) analyzed on apolar column A. The peaks are numbered according to the information in Table 1 . The minor VOCs P1-P10 were not visible in these chromatograms. Note that the concentrations of compounds 87 to 96 are so similar that the black chromatogram of lamb US-2007-0224 is only visible at the apexes of the peaks

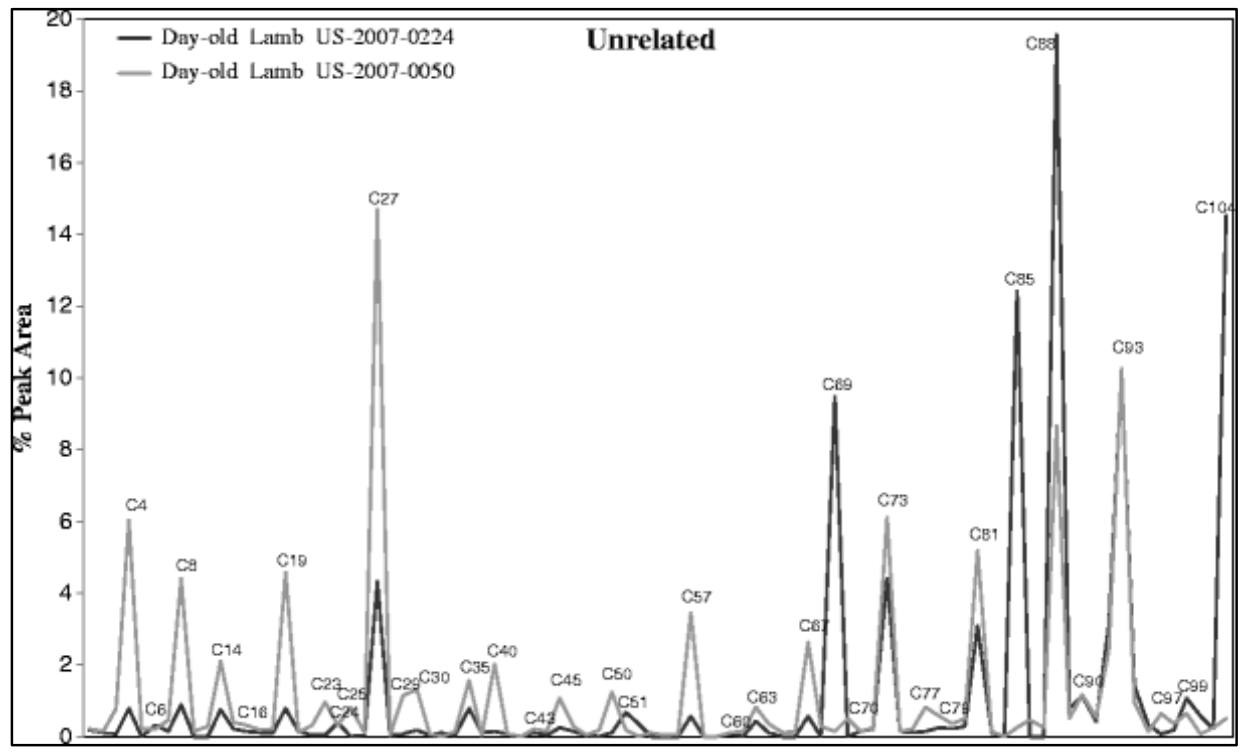

Fig. 2 Comparison of the percentage peak areas derived from mass chromatograms of the sample-enrichment-probeenriched wool volatiles of the unrelated lambs US-2007-0224 (black) and US-2007-0050 (grey). The peaks are numbered according to Table $\underline{1}$ 


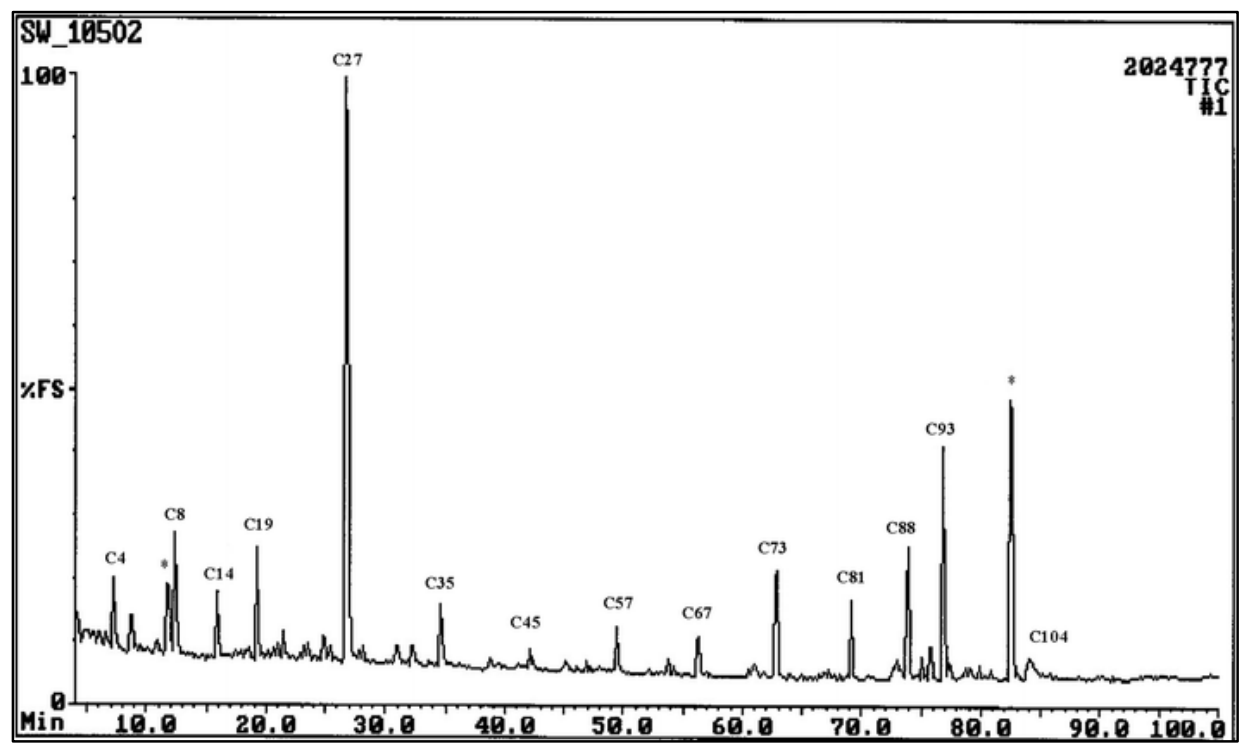

Fig. 3 Total ion chromatogram (TIC) of the headspace of the wool of Döhne Merino lamb US-2007-0105 analyzed on apolar column A. The peaks are numbered according to Table $\underline{1}$. Two impurities, present in all samples, are indicated by an asterisk

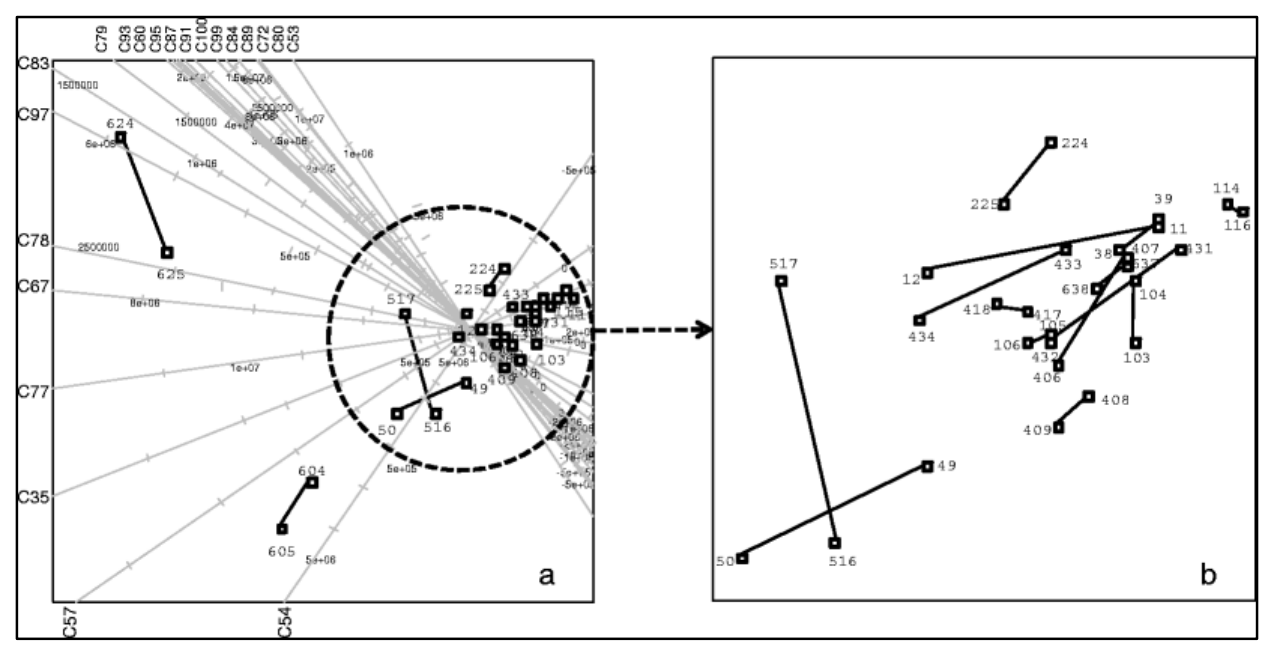

Fig. 4 a Principal component analysis biplot for the wool volatiles collected from day-old lambs during the lambing season of 2007; b PCA biplot displaying a magnified view of the crowded area in Fig. $\underline{4 a}$. Lambs possessing similar odor profiles are circled. For identities of chemical codes refer to Table $\underline{1}$ 


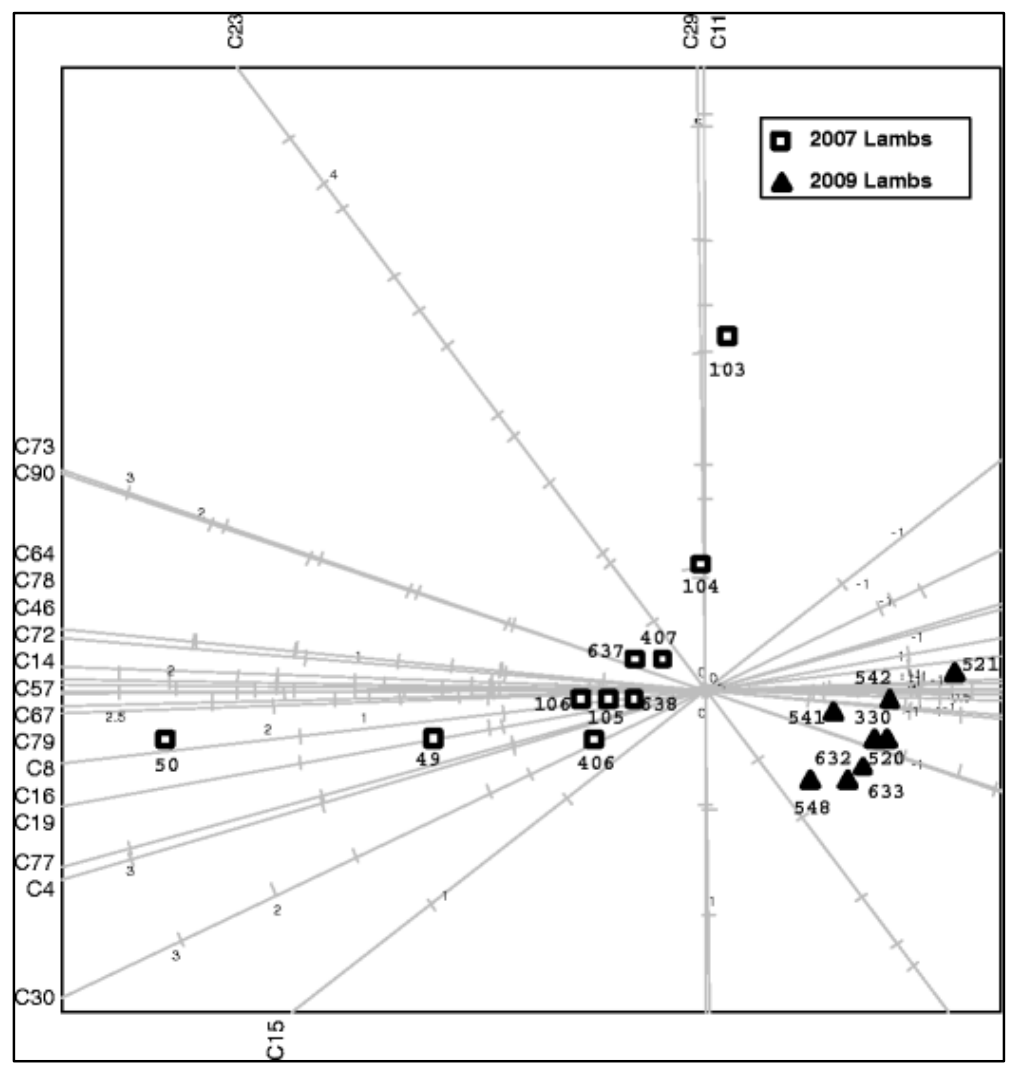

Fig. 5 Principal component analysis biplot for the wool volatiles collected from day-old lambs during the lambing seasons of 2007 and 2009. For identities of chemical codes refer to Table $\underline{1}$ 


\section{References}

1. Adams, D. and McKinley, M. 1995. The Sheep, ANZCCART News 8(2). Revised by Colditz, I., and Dart, C. 2009. ANZCCART Fact Sheet A9, University of Adelaide.

2. Alberts, A. C. 1992. Constraints on the design of chemical communication systems in terrestrial vertebrates. Am. Nat. 139:S62-S89.

3. Aldrich, C., Gardner, S., and Le Roux, N. J. 2004. Monitoring of metallurigal process plants using biplots. J. Am. Inst. Chem. Eng. 50:2167-2186. doi:10.1002/aic.10170

4. Alexander, G. 1978. Odour, and the recognition of lambs by Merino ewes. Appl. Anim. Ethol. 4:153-158.

5. Alexander, G. and Shillito, E. E. 1977. The importance of odour, appearance and voice in maternal recognition of the young in Merino sheep (Ovis aries). Appl. Anim. Ethol. 3:127-135.

6. Alexander, G. and Stevens, D. 1981. Recognition of washed lambs by Merino ewes. Appl. Anim. Ethol. 7:77-86.

7. Alexander, G., Stevens, D., and Bradley, L. R. 1983. Washing lambs and confinement as aids to fostering. Appl. Anim. Ethol. 10:251-261.

8. Alexander, G., Stevens, D., and Bradley, L. R. 1987. Fostering in sheep: experiences with the use of neatsfoot oil. Austr. J. Exp. Agric. 27:771-778.

9. Alexander, G., Goodrich, B. S., Stevens, D., and Bradley, L. R. 1989a. Maternal interest in lambs smeared with polar and nonpolar substances. Austr. J. Exp. Agric. 29:513-515.

10. Alexander, G., Stevens, D., and Bradley, L. R. 1989b. Fostering in sheep: an exploratory comparison of several approaches. Austr. J. Exp. Agric. 29:509-512.

11. Brennan, P. A. and Kendrick, K. M. 2006. Mammalian social odours: attraction and individual recognition. Phil. Trans. R. Soc. B 361:2061-2078.

12. Burger, B. V., Marx, B., Le Roux, M., and Burger, W. J. G. 2006. Simplified analysis organic compounds in headspace and aqueous samples by high-capacity sample enrichment probe. J. Chrom. A 1121:259-267.

13. Burger, B. V., Viviers, M. Z., Bekker, J. P. I., Le Roux, M., Fish, N., Fourie, W. B., and Weibchen, G. 2008. Chemical characterization of territorial marking fluid of male Bengal tiger, Panthera tigris. J. Chem. Ecol. 34:659-671.

14. Burger, B. V., le Roux, M., Marx, B., Herbert, S. A., and Amakali, K. T. 2011. Deverlopment of second-generation sample enrichment probe for improved sortive analysis of volatile organic compounds. J. Chrom. A 1218:15671575.

15. Dwyer, C. M. 2008. Genetic and physiological determinants of maternal behaviour and lamb survival: implications for low-input sheep management. J. Anim. Sci. 86:E246-E258.

16. Gardner-Lubbe, S., Le Roux, N. J., and Gower, J. C. 2008. Measures of fit in principal component and canonical variate analyses. J. Appl. Statist. 35:947-965.

17. Gower, J. C. and Hand, D. J. 1996. Biplots. Chapman Hall, London.

18. Grob, K. 1973. Organic substances in potable water and its precursors Part I. Methods for their determination by gas-liquid chromatography. J. Chromatogr. 84:255-273.

19. Houpt, K. A. 2005. Domestic Animal Behaviour for Veterinarians and Animal Scientists. Fourth Edition, Blackwell, Oxford.

20. Kendrick, K. M., Lévy, F., and Keverne, E. B. 1992. Changes in the sensory processing of olfactory signals induced by birth in sheep. Science 256:833-836.

21. Kovats, E. 1958. Gas-chromatographische Charakterisierung organischer Verbindungen. Teil 1: Retentionsindices aliphatischer Halogenide, Alkohole, Aldehyde und Ketone. Helv. Chim. Acta 41:1915-1932.

22. Kowalski, B. R. and Bender, C. F. 1972. Pattern recognition. A powerful approach to interpreting chemical data. J. Am. Chem. Soc. 94:5632-5639.

23. Lévy, F., Poindron, P., and Le Neindre, P. 1983. Attraction and repulsion by amniotic fluids and their olfactory control in the ewe around parturition. Physiol. Behav. 31:687-692.

24. Lévy, F., Keller, M., and Poindron, P. 2004. Olfactory regulation of maternal behavior in mammals. Horm. Behav. 46:284-302.

25. Lindsay, D. 1988. Breeding the Flock: Modern Research and Reproduction in Sheep. Inkata, Melbourne.

26. Lisovac, A. M. and Shooter, D. 2003. Volatiles from sheep wool and the modification of wool odours. Small Ruminant Res. 49:115-124.

27. Lynch, J. J, Hinch, G. N., and Adams, D. B. 1992. The behaviour of sheep. Biological principles and implications for production. C.A.B International and CSIRO Australia, Melbourne.

28. Maas, B., Dietrich, A., and Mosandl, A. 1994. Collection of enantiomer separation factors obtained by capillary gas chromatography on chiral stationary phases. J. High Resolut. Chrom. 17:109-115.

29. Motiuk, K. 1979a. Wool wax acids: a review. J. Am. Oil Chem. Soc. 56:91-97. 
30. Motiuk, K. 1979b. Wool wax alcohols: a review. J. Am. Oil Chem. Soc. 56:651-658.

31. Motiuk, K. 1980. Wool wax hydrocarbons: a review. J. Am. Oil Chem. Soc. 57:145-146.

32. Poindron, P., Gilling, G., Hernandez, H., Serafin, N., and Terrazas, A. 2003. Early recognition of newborn goat kids by their mother: 1. Non-olfactory discrimination. Dev. Psychobiol. 43:82-89.

33. Poindron, P., Lévy, F., and Keller, M. 2006. Maternal responsiveness and maternal selectivity in domestic sheep and goats: the two facets of maternal attachment. Dev. Psychobiol. 49:54-70.

34. Price, E. O., Dunn, G. C., Talbot, J. A., and Dally, M. R. 1984. Fostering lambs by odor transfer: the substitution experiment. J. Anim. Sci. 59:301-307.

35. Price, E. O., Dally, M. R., and Hernandez, L. 2003. A note on the use of odor manipulation to facilitate the adoption of alien lambs by ewes bearing twins. Appl. Anim. Behav. Sci. 81:127-131. Reiter, B., Burger, B. V., and Dry, J. 2003. Mammalian exocrine secretions XVIII. Chemical characterization of interdigital secretion of red hartebeest, Alcelaphus buselaphus Caama. J. Chem. Ecol. 29:2235-2252.

36. Rietdorf, M. 2002. Identifizierung und Synthese flüchtiger Substanzen aus Säugetieren. PhD Thesis, Institut für Organische Chemie, Universität Hamburg.

37. Romeyer, A., Porter, R. H., Poindron, P., Orgeur, P., Chesné, P., and Poulin, N. 1993. Recognition of dizygotic and monozygotic twin lambs by ewes. Behaviour 127:119-139.

38. Schlossman, M. L. and McCarthy, J. P. 1979. Lanolin and derivatives chemistry: relationship to allergic contact dermatitis. Contact Dermatitis 5:65-72.

39. Vince, M. A., Lynch, J. J., Mottershead, B., Green, G., and Elwin, R. 1985. Sensory factors involved in immediately postnatal ewe/lamb bonding. Behaviour 94:60-84.

40. Vincenti, M., Guglielmetti, G., Cassani, G., and Tonini, C. 1987. Determination of double bond position in diunsaturated compounds by mass spectrometry of dimethyl disulfide derivatives. Anal. Chem. 59:694-699.

41. Wyatt, T. D. 2003. Pheromones and animal behaviour. Communication by smell and taste. Cambridge University Press, Cambridge.

42. Wyatt, T. D. 2010. Pheromones and signature mixtures: defining species-wide signals and variable cues for identity in both invertebrates and vertebrates. J. Comp. Physiol. A. 196:685-700.

43. Yamazaki, K., Boyse, E. A., Mike, V., Thaler, H. T., Mathieson, B. J., Abbott. J., Boyse, J. Zayas, Z. A., and Thomas, L. 1976. Control of mating preferences in mice by genes in major histocompatibility complex. J. Exp. Med. 144:1324-1335. 


\section{Supplementary Information}

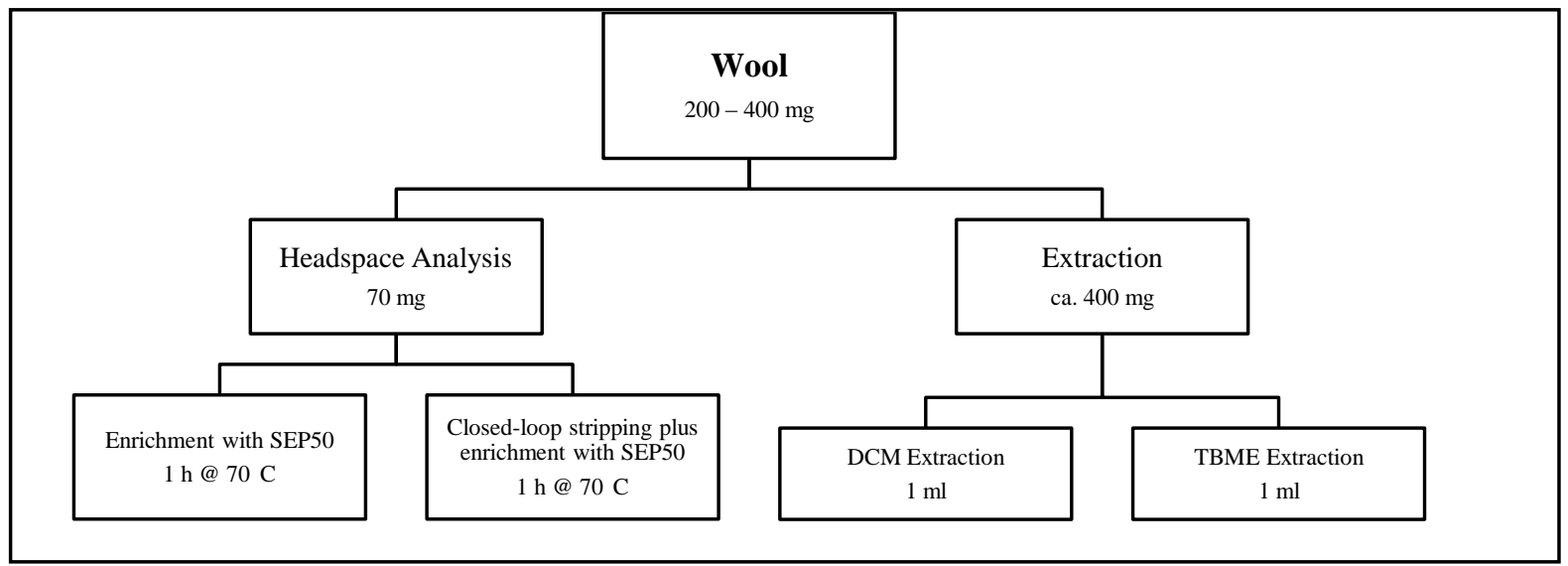

Fig. S1. Wool sample allocation for gas chromatography-mass spectrometry analysis

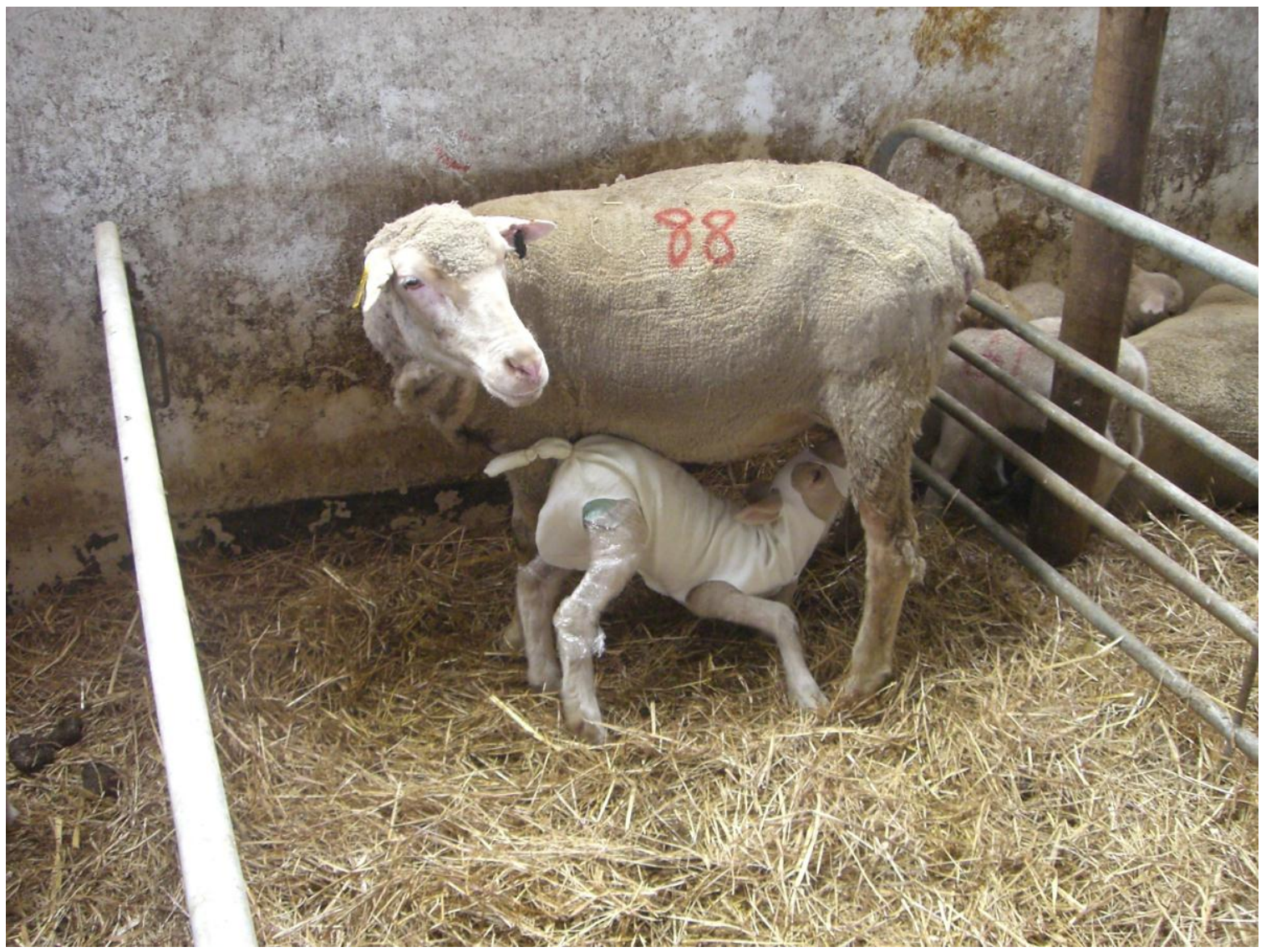

Fig.S2. Diapered and wrapped alien lamb dressed in a cotton fleece jacket worn for $24 \mathrm{hr}$ by the ewe's own lamb. 


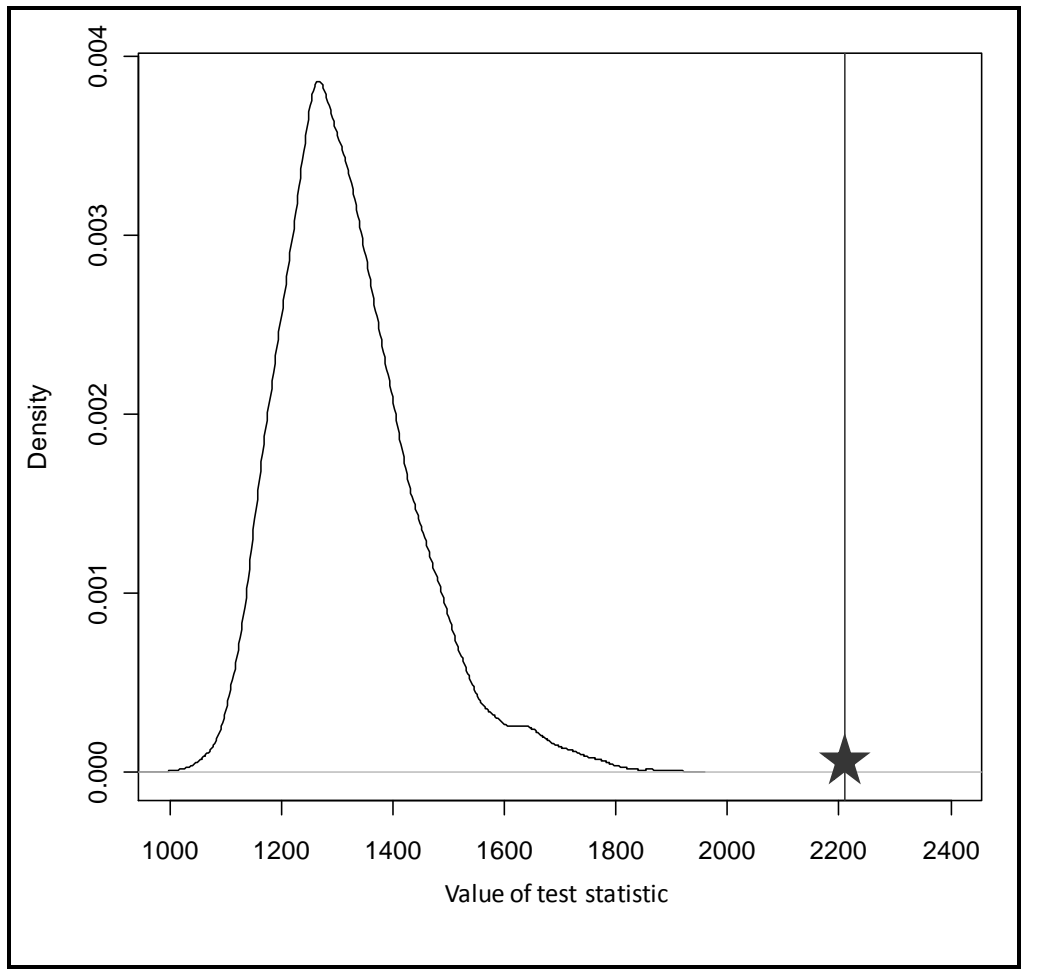

Fig. S3. Permutation distribution of the test statistic showing the differences in the composition of the wool volatiles collected from day-old twin lambs compared to the rest of the group of lambs. The calculated $P$-value $<0.001$ is indicated by the vertical line on the right hand side of the figure. Twin lambs thus possess odor profiles that are unique and their odor profiles are more similar than those of other randomly selected non-twin lambs.

\section{Synthesis of Reference Compounds.}

Some of the compounds that were required as standards for the confirmation of the structures of constituents identified in this study were available from previous studies in our laboratory, or from the South African distributors of the products of Sigma-Aldrich, Merck, Saarchem, NT Laboratories and B.D.H.; others were synthesized from commercially available starting materials as described below. The structures of all of the compounds that were synthesised in the present investigation were verified by GC-MS, ${ }^{1} \mathrm{H}$ and ${ }^{13} \mathrm{C}$ NMR spectrometry. Some of the synthesized compounds belong to homologous series of the respective long-chain compounds. The NMR spectra of compounds belonging to these homologous series are practically identical 
and the ${ }^{13} \mathrm{C}$ NMR data of only one example of each compound class are included in the information below.

Preparation of 2,6,10,14-tetramethylhexadecane. A solution of $(6 E, 10 E)-7,11,15$-trimethyl-3methylenehexadeca-1,6,10,14-tetraene (Burger et al., 1978) $(0.25 \mathrm{~g}, 0.92 \mathrm{mmol}$ ) in glacial acetic acid (50 ml) was hydrogenated using platinum on activated charcoal $(10 \% \mathrm{Pt} / \mathrm{C})$ as catalyst. The hydrogenation was carried out at approximately atmospheric pressure and the consumption of hydrogen was monitored volumetrically. The reaction was allowed to run to completion, the reaction mixture diluted with an equal volume of distilled water, and then extracted with $\mathrm{CHCl}_{3}(3 \times 10 \mathrm{ml})$. The combined extracts were washed with water to neutral $\mathrm{pH}$ and dried on anhydrous $\mathrm{MgSO}_{4}$, after which the drying agent was filtered off and the solvent removed on a rotary evaporator to yield 2,6,10,14tetramethylhexadecane in quantitative yield with a purity of 91\% (GC-MS). MS (70 eV): $\mathrm{m} / \mathrm{z}(\%)$ 282( $\left.\mathrm{M}^{+}, 0.07\right), 267(0.13), 253(0.17), 197(3), 183(4), 155(3), 141(5), 127(7), 113(8), 99(14)$, 85(44), 71(84), 57(100), 43(52). ${ }^{13} \mathrm{C} \mathrm{NMR}(\mathrm{CDCl} 3,101 \mathrm{MHz}): \delta=11.45$ (q, C-16), 19.26 (q, C-20)3, $19.32\left(q, C-19^{*}\right) 4,19.81\left(q, C-18^{*}\right), 22.68\left(q, C-17^{*}\right), 22.77(q, C-1 *), 24.54$ (t, C-8*), 24.55 (t, C$\left.12^{*}\right), 24.86\left(t, C-4^{*}\right), 28.04$ (d, C-2), 29.63 (t, C-15), 32.83 (d, C-6*), 32.87 (d, C-10*), 34.49 (d, C14), $37.01(t), 37.35(t), 37.45(t), 37.46(t), 37.52(t), 39.44(t, C-3)$.

Note. * exchangeable assignments

Preparation of branched primary alcohols. Primary isoalcohols and ante-isoalcohols were synthesized from the corresponding branched carboxylic acids according to a scaled-down version of the protocol of Tietze and Eicher (1981: 416), as exemplified by the synthesis of 15methyl-1-hexadecanol. The resulting alcohols were used as starting materials for the 
preparation of the branched aldehydes described below. Note. Methyl substituents are numbered in order of their attachment to carbon atoms with ascending numbers in the parentchain.

15-Methyl-1-hexadecanol. 15-Methylhexadecanoic acid (8.00 mg; $0.03 \mathrm{mmol})$ in TBME (200 $\mu \mathrm{l})$ was placed in a $2 \mathrm{ml}$ Reacti-Vial, with a small-vaned magnetic follower, and treated with an excess of a clear standardized solution of $\mathrm{LiAlH}_{4}$ in dry diethyl ether. The Reacti-Vial was sealed and the reaction mixture stirred at $60^{\circ} \mathrm{C}$ for $3 \mathrm{hr}$. The excess $\mathrm{LiAlH}_{4}$ was decomposed by the dropwise addition of water $(500 \mu l)$ with stirring. The white precipitate was dissolved by the addition of a few drops of conc. $\mathrm{H}_{2} \mathrm{SO}_{4}(350 \mu \mathrm{l})$. The organic phase was separated from the aqueous phase and the aqueous phase extracted with TBME (100 $\mu l)$. The combined extracts were washed to neutral $\mathrm{pH}$ with water and dried on anhydrous $\mathrm{MgSO}_{4}$. The drying agent was filtered off and the solvent removed on a rotary evaporator to yield 15-methyl-1-hexadecanol (6.00 mg, 79\%), with a purity of 95\% (GC-MS). MS (70 eV): $m / z(\%) 238(1.3), 210(4), 182(4)$, 111(25), 97(42), 83(60), 69(78), 57(87), 55(86), 43(100), 41(74).

8-Methyl-1-nonanol MS (70 eV): m/z (\%) 140(M+1 4), 126(14), 112(11), 111(17), 97(14), 85(50), 83(30), 71(51), 70(52), 69(79), 57(74), 56(58), 55(65), 43(100), 41(84).

11-Methyl-1-tridecanol. MS (70 eV): m/z (\%) 196(0.04), 168(1.5), 166(2), 139(4), 125(25), 97(50), 83(72), 71(80), 69(100), 57(85), 55(94), 43(50), 41(62).

12-Methyl-1-tridecanol. MS (70 eV): m/z (\%) 196(0.5), 168(4), 140(6), 125(4), 111(7), 97(33), 83(56), 69(84), 57(84), 56(100), 55(88), 43(93), 41(81).

13-Methyl-1-tetradecanol. MS (70 eV): m/z (\%) 210(0.02), 140(0.2), 125(3), 111(4), 97(18), 83(32), 69(100), 57(33), 56(92), 55(95), 43(72), 41(62). 
14-Methyl-1-pentadecanol. MS (70 eV): m/z (\%) 224(0.8), 196(4), 168(5), 140(4), 125(6), 111(21), 97(39), 83(59), 69(81), 57(86), 56(86), 55(84), 43(100), 41(78).

14-Methyl-1-hexadecanol. MS (70 eV): m/z (\%) 238(0.5), 210(3), 125(13), 111(30), 97(65), 83(79), 70(98), 57(92), 55(100), 43(72), 41(88).

Preparation 2-pentadecanol. Following the protocol of Brown and Geoghegan (1967), 1pentadecene $(4.80 \mathrm{~g}, 0.022 \mathrm{~mol})$ was added to a solution of mercuric acetate $(7.01 \mathrm{~g}, 0.022$ $\mathrm{mol})$, in water $(22 \mathrm{ml})$ and purified tetrahydrofuran $(22 \mathrm{ml})$, in a $150-\mathrm{ml}$ round-bottom flask containing a magnetic follower (stir bar). The reaction mixture was stirred for $1.5 \mathrm{hr}$ at room temperature to complete the oxymercuration stage. Sodium hydroxide solution ( $20 \mathrm{ml}, 3 \mathrm{M})$ was then added, followed by a solution of sodium borohydride $(20 \mathrm{ml}, 0.5 \mathrm{M})$ in sodium hydroxide $(3.0 \mathrm{M})$. The mercury was allowed to settle and the reaction mixture diluted with purified diethyl ether $(20 \mathrm{ml})$. The organic phase was separated from the aqueous phase and dried on anhydrous $\mathrm{MgSO}_{4}$. The drying agent was filtered off, and the solvent removed on a rotary evaporator to yield 2-pentadecanol ( $2.88 \mathrm{~g}, 57 \%)$, with a purity of $82 \%$ (GC-MS). MS (70 eV): $m / z(\%)$ 210(2), 125(6), 111(8), 97(15), 83(12), 69(12), 57(20), 55(23), 45(100), 43(41).

This product was used for the preparation of 2-pentadecanone as described below.

Preparation of 6,10,14-trimethyl-2-pentadecanol. 6,10,14-Trimethyl-2-pentadecanone (hexahydrofarnesyl acetone) $(50 \mu \mathrm{l}, 0.15 \mathrm{mmol})$ in TBME $(100 \mu \mathrm{l})$ was placed in a $2 \mathrm{ml}$ Reacti-Vial with a magnetic follower and reduced with $\mathrm{LiAlH}_{4}$, as described above for the primary alcohols, to yield 6,10,14-trimethyl-2-pentadecanol (31.87 mg, 91\%), with a purity of 93\% (GC-MS). MS (70 eV): $m / z$ (\%) 210(0.3), 196(1), 182(2), 167(1), 140(3), 125(17), 111(24), 97(44), 83(25), 


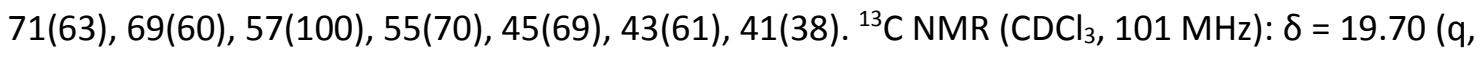
C-16), 19.77 (q, C-17), 22.64 (q, C-18*), 22.74 (q, C-15*), 23.44 (t, C-8), 23.53 (q, C-1), 24.68 (t, C$\left.4^{*}\right), 24.83\left(t, C-12^{*}\right), 28.00$ (d, C-14), $32.79\left(\mathrm{~d}, \mathrm{C}-10^{*}\right), 32.81\left(\mathrm{~d}, \mathrm{C}-6^{*}\right), 37.05$ (t, C-5*), 37.15 (t, C$\left.7^{*}\right), 37.30(t, C-9 *), 37.41\left(t, C-11^{*}\right), 39.39\left(t, C-13^{*}\right), 39.75(t, C-3 *), 68.19$ (d, C-2).

Preparation of aldehydes. Branched and unbranched aldehydes were synthesized by oxidation of the corresponding primary alcohols with pyridinium chlorochromate (PCC), according to Harwood et al. (2003), in yields ranging from 53 to $84 \%$, as exemplified by a microscale preparation of 15-methylhexadecanal from 15-methyl-1-hexadecanol.

15-Methylhexadecanal. 15-Methyl-1-hexadecanol (6.00 mg, $0.023 \mathrm{mmol})$, dissolved in DCM (1 $\mathrm{ml}$ ) was added dropwise to a magnetically stirred suspension of PCC (7.58 $\mathrm{mg}, 0.352 \mathrm{mmol})$ in DCM $(200 \mu \mathrm{l})$ at 0 으. The reaction mixture was stirred at room temperature for $2 \mathrm{~h}$, diluted with dry diethyl ether $(50 \mu \mathrm{l})$ and the supernatant solution decanted from the black residue. The residue was washed with diethyl ether $(3 \times 30 \mu \mathrm{l})$, employing centrifugal separation of the phases, and the combined ether and DCM phases filtered through a short column of silica gel. The solution was dried on anhydrous $\mathrm{MgSO}_{4}$, then the drying agent filtered off and the solvent removed on a rotary evaporator to yield 15 -methylhexadecanal $(5.00 \mathrm{mg}, 84 \%)$, with a purity of 98\% (GC-MS). MS (70 eV): m/z (\%) 254(M+ $\left.\mathrm{M}^{+}, 0.1\right), 236(0.3), 210(1), 208(2), 180(2), 154(2), 152(3)$, 137(4), 123(8), 109(14), 96(23), 95(31), 82(40), 81(43), 69(61), 67(47), 57(100), 55(71), 43(91), 41(62). 13C NMR (CDCl3, 150.88 MHz): $\delta=22.70$ (q, C-16, C-17), 28.01 (d, C-15), 29.10 (t), 29.21 $(t), 29.27(t), 29.39(t), 29.47(t), 29.63(t), 29.67(t), 29.70(t), 29.75(t), 29.98(t), 33.82(t, C-3)$, 39.10 (t, C-14), 43.96 (t, C-2), 203.03 (d, C-1). 
3-Methylpentanal. MS (70 eV): $m / z(\%)$ 100( $\left.\mathrm{M}^{+}, 6\right), 82(2), 71(19), 58(39), 57(50), 56(100), 44(55)$, 43(79), 41(86). ${ }^{13} \mathrm{C} \mathrm{NMR}(\mathrm{CDCl} 3,75.38 \mathrm{MHz}$ ): $\delta=11.23$ (q, C-5), 19.45 (q, C-6), 29.69 (t, C-4), 31.68 (d, C-3), 41.15 (t, C-2), 203.21 (d, C-1).

8-Methylnonanal. MS (70 eV): m/z (\%) 138(0.4), 128(4), 114(6), 110(7), 95(34), 82(45), 81(31), 71(31), 69(45), 67(27), 57(93), 55(56), (100), 41(95).

11-Methyltridecanal. MS (70 eV): $m / z(\%) 212(\mathrm{M}+, 0.1), 194(0.4), 184(0.7), 183(1), 166(2)$, 165(3), 139(3), 138(2), 137(5), 123(6), 109(26), 96(28), 95(46), 83(42), 82(38), 81(40), 70(59), 69(40), 67(36), 57(95), 55(78), 43(67), 41(100).

12-Methyltridecanal. MS (70 eV): $m / z$ (\%) 212( $\left.\mathrm{M}^{+}, 0.1\right), 194(0.4), 184(1), 168(2), 166(2), 153(2)$, 151(2), 140(3), 138(3), 137(4), 123(7), 110(8), 109(16), 96(20), 95(37), 83(40), 81(47), 71(35), 69(61), 67(45), 57(100), 55(74), 43(92), 41(67).

13-Methyltetradecanal. MS (70 eV): $m / z$ (\%) 208(2), 182(3), 180(2), 154(2), 152(2), 137(3), 124(6), 123(6), 109(12), 96(26), 95(28), 82(46), 71(25), 69(43), 68(31), 67(31), 57(79), 55(60), 43(100), 41(83).

14-Methylpentadecanal. MS (70 eV): m/z (\%) 222(1), 212(1), 196(1), 194(2), 166(2), 164(2), 152(2), 138(3), 137(4), 124(5), 123(6), 109(14), 96(28), 95(30), 83(31), 82(51), 81(30), 69(43), 57(79), 55(70), 43(100), 41(81).

14-Methylhexadecanal. MS (70 eV): m/z (\%) 236(1), 225(1), 208(1), 181(1), 151(2), 137(5), 123(9), 109(21), 96(30), 95(41), 82(45), 81(45), 70(64), 69(49), 67(35), 57(100), 55(79), 43(77), 41(92). ${ }^{13} \mathrm{C} \mathrm{NMR}\left(\mathrm{CDCl}_{3}, 150.88 \mathrm{MHz}\right): \delta=11.44$ (q, C-16), 19.26 (q, C-17), 24.73 (t, C-12), 29.10 $(t, C-11), 29.27(t), 29.53(t, 2 \times C), 29.62(t), 29.67(t), 29.70(t), 29.75(t), 30.06(t), 31.96(t, C-3)$, 34.44 (d, C-14), 36.68 (t, C-13), 43.95 (t, C-2), 203.00 (d, C-1).

Tetradecanal. MS (70 eV): m/z (\%) 212(M+1 0.13), 194(1), 184(1), 168(5), 166(3), 138(7), 124(9),

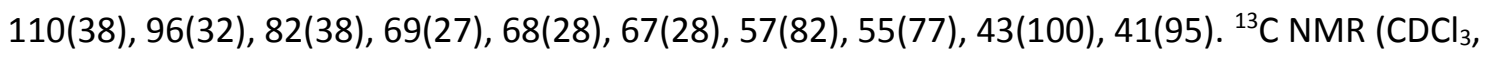


$101 \mathrm{MHz}): \delta=14.11(\mathrm{q}, \mathrm{C}-14), 22.11(\mathrm{t}, \mathrm{C}-13), 22.71(\mathrm{t}, \mathrm{C}-12), 29.09(\mathrm{t}), 29.19(\mathrm{t}), 29.27(\mathrm{t}), 29.38$ $(t), 29.45(t), 29.61(t), 29.67(t), 29.69(t), 31.94(t, C-3), 43.92(t, C-2), 203.00(d, C-1)$.

Pentadecanal. MS (70 eV): $m / z$ (\%) 226( $\left.\mathrm{M}^{+}, 0.2\right), 208(2), 182(4), 180(3), 152(5), 138(6), 124(8)$, 110(14), 96(40), 82(44), 69(22), 68(23), 67(22), 57(65), 55(61), 43(93), 41(100).

Hexadecanal. MS (70 eV): $m / z(\%)$ 240(M+, 0.2), 222(2), 194(3), 166(3), 152(3), 138(6), 124(10), 110(16), 109(15), 96(45), 82(53), 69(25), 68(26), 67(25), 57(61), 55(58), 43(100), 41(94).

Heptadecanal. MS (70 eV): $m / z$ (\%) 254(M+1 0.2$), 236(2), 210(3), 208(3), 180(2), 152(3), 138(6)$, 137(5), 124(10), 123(8), 110(15), 109(14), 96(43), 82(47), 69(23), 68(23), 67(22), 57(60), 55(57), 43(100), 41(85).

Preparation of methyl ketones. Methylketones were prepared by PCC oxidation, according to Harwood et al. (2003), from the corresponding secondary alcohols, as described in the previous section.

2-Tetradecanone. MS (70 eV): $m / z(\%) 212\left(\mathrm{M}^{+}, 4\right), 197(2), 154(4), 153(3), 127(2), 111(2), 110(2)$, 96(6), 85(11), 71(42), 59(48), 58(100), 55(18), 43(96), 41(33). $\left.{ }^{13} \mathrm{C} \mathrm{NMR} \mathrm{(CDCl3,} 75.38 \mathrm{MHz}\right): \delta=$ $14.10(q, C-14), 22.68(t, C-13), 23.88(t, C-4), 29.18(t), 29.35(t), 29.40(t), 29.47(t), 29.53(t)$, $29.61(t), 29.65(q, C-1), 29.81(t), 31.92(t, C-12), 43.81(t, C-3), 209.30(d, C-2)$.

2-Pentadecanone. MS (70 eV): $m / z$ (\%) 226( $\left.\mathrm{M}^{+}, 7\right), 211(3), 168(6), 138(3), 127(5), 110(5), 96(11)$, 85(17), 71(39), 59(68), 58(92), 43(100), 41(55).

Preparation of 6,10-dimethyl-2-undecanone. 6,10-Dimethyl-5,9-undecadien-2-one (geranylacetone) $(0.25 \mathrm{~g}, 1.29 \mathrm{mmol})$ was hydrogenated in glacial acetic acid (50 ml) using platinum on activated charcoal $(10 \% \mathrm{Pt} / \mathrm{C})$ as catalyst at atmospheric pressure. The consumption of hydrogen was monitored and was terminated after the consumption of a volume of hydrogen equivalent to the reduction of two double bonds. The reaction mixture was then diluted with an equal volume of distilled water and extracted with $\mathrm{CHCl}_{3}(3 \times 10 \mathrm{ml})$. The combined extracts 
were washed with water to neutral $\mathrm{pH}$ and dried on anhydrous $\mathrm{MgSO}_{4}$, after which the drying agent was filtered off and the solvent removed on a rotary evaporator to yield 6,10-dimethyl-2undecanone $(0.24 \mathrm{~g}, 95 \%)$, with a purity of $88 \%$ (GC-MS). MS (70 eV): $\mathrm{m} / \mathrm{z}(\%)$ 198( $\left.\mathrm{M}^{+}, 0.4\right)$,

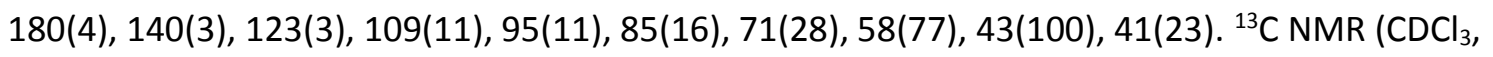
100.58 MHz): $\delta=19.55$ (q, C-12), 21.44 (t, C-4), 22.69 (q, $2 \times$ C), 24.73 (t, C-8), 27.96 (d, C-10), 29.83 (q, C-1), 32.65 (d, C-6), 36.52 (t, C-7), 37.10 (t, C-5), 39.32 (t, C-9), 44.14 (t, C-3), 209.35 (d, C-2).

\section{References}

1. Brown, H. C. and Geoghegan, P. 1976. The oxymercuration-demercuration of representative olefins. A convenient, mild procedure for the Markovnikov hydration of the carbon-carbon double bond. J. Am. Chem. Soc. 89: 1522-1524.

2. Burger, B. V., Le Roux, M., Spies, H. S. C., Truter, V. and Bigalke, R. C. 1978. Mammalian pheromone studies, III. $(E, E)-7,11,15-T r i m e t h y l-3-m e t h y l e n e h e x a d e c a-1,6,10,14-$ tetraene, a new diterpene analogue of b-farnesene from the dorsal gland of the springbok, Antidorcas marsupialis. Tetrahedron Lett. 52: 5221-5224.

3. Harwood, L. M., Moody, C. J. and Percy, J. M. 2003. Experimental organic chemistry. Standard and microscale. $2^{\text {nd }}$ ed, Blackwell Science, Germany. Experiment 31, pp 507510.

4. Tietze, L.-F. and Eicher, T. 1981. Reaktionen und Synthesen im organish-chemischen Praktikum. Georg Thieme, Stuttgart, Germany. 